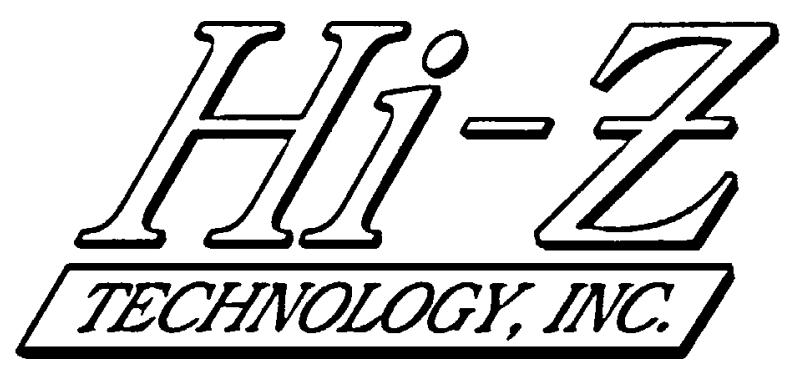

Final Report

\title{
Clean Diesel Engine Component Improvement Program Diesel Truck Thermoelectric Generator
}

\author{
Prepared by
}

N. B. Elsner, J. C. Bass, S. Ghamaty, D.Krommenhoek, A. Kushch, D. Snowden, and S. Marchetti

Prepared for

Contract DE-FC05-00OR22812

DE-FC26-00OR22812

DOE Program Manager: John Fairbanks

Subcontractors

PACCAR Technical Center

Contact: Rich Bergstrand

March 16, 2005 


\section{Hi-Z Technology, Inc.}

\section{Final Report \\ Clean Diesel Engine Component Improvement Program \\ Diesel Truck Thermoelectric Generator}

This material is based upon work supported by the U.S. Department of energy under Awards:

$$
\begin{aligned}
& \text { DE-FC05-00OR22812 } \\
& \text { DE-FC26-00OR22812 }
\end{aligned}
$$

Any opinions, findings, and conclusions or recommendations expressed in this material are those of the authors and do not necessarily reflect the view fo the Department of Energy. 


\section{DISCLAIMER}

This report was prepared as an account of work sponsored by an agency of the United States Government. Neither the United States Government nor any agency thereof, nor any of their employees, makes any warranty, express or implied, or assumes any legal liability or responsibility for the accuracy, completeness, or usefulness of any information, apparatus, product, or process disclosed, or represents that its use would not infringe privately owned rights. Reference herein to any specific commercial product, process, or service by trade name, trademark, manufacturer, or otherwise does not necessarily constitute or imply its endorsement, recommendation, or favoring by the United States Government or any agency thereof. The views and opinions of authors expressed herein do not necessarily state or reflect those of the United States Government or any agency thereof. 


\section{Table of Contents}

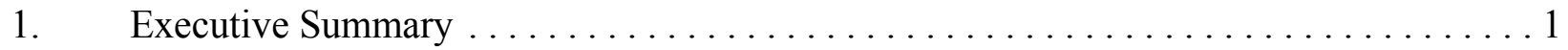

2. Comparison of Actual Accomplishments With Objectives . . . . . . . . . . . 1

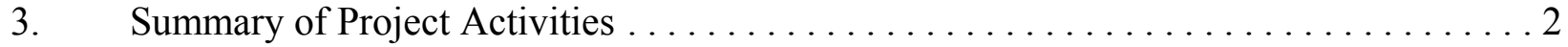

3-A. DTTEG Development With Bulk Material T/E Modules $\ldots \ldots \ldots \ldots \ldots \ldots$

3-B. Quantum Well Development by Sputtering . . . . . . . . . . . . . . 10

3-C. Quantum Well Development by Electron Beam Hot Wall . . . . . . . . . . . 11

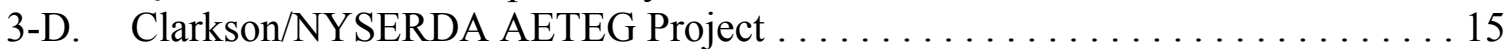

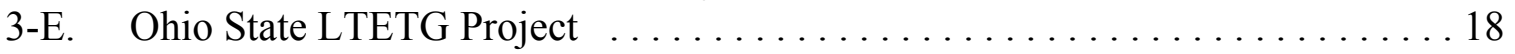

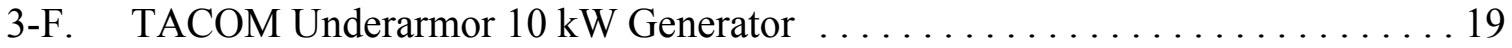

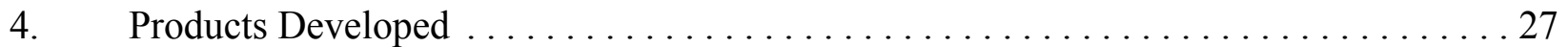

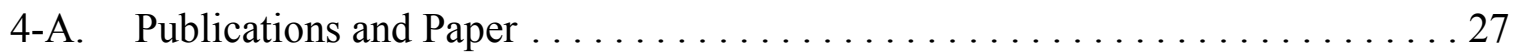

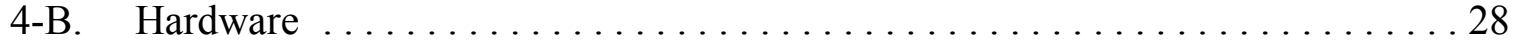

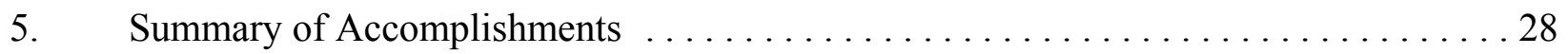

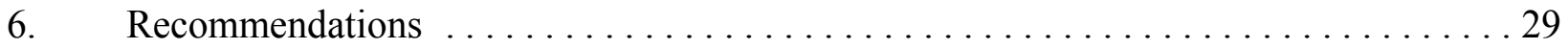




\section{List of Figures}

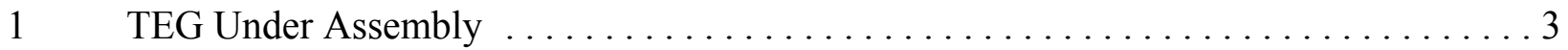

2 TEG Heat Exchanger with all TE Modules, Electrical Wring and Heat Sinks . . . . . . 3

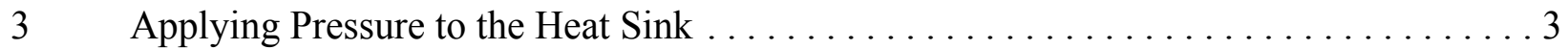

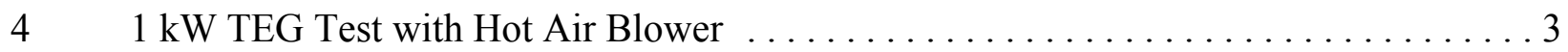

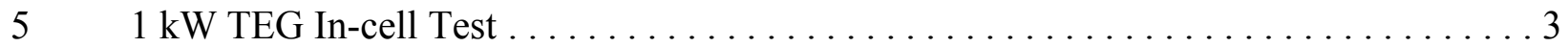

6 TEG Power Output as a Function of the Engine Load and Speed . . . . . . . . . 4

7 TEG Mounted on the Truck Frame with Shock Absorption Bracket $\ldots \ldots \ldots \ldots \ldots$

8 TEG Mounted on the Truck Frame $\ldots \ldots \ldots \ldots \ldots \ldots \ldots \ldots \ldots \ldots$

9 TEG Mounted on the Truck, View From the Bottom $\ldots \ldots \ldots \ldots \ldots \ldots \ldots$

10 Kenworth Class Eight Diesel Truck With Integrated TEG (under the cabin)

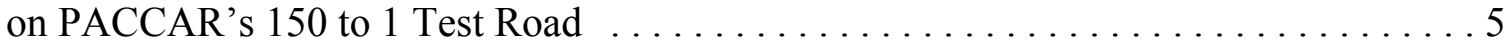

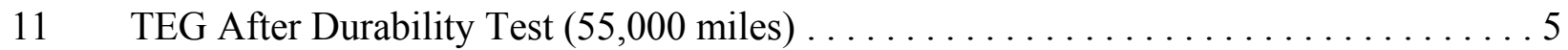

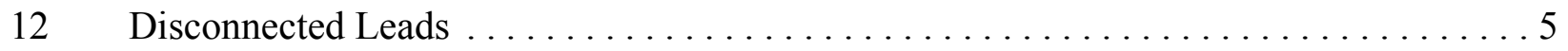

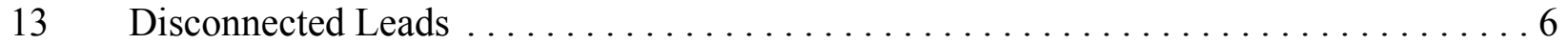

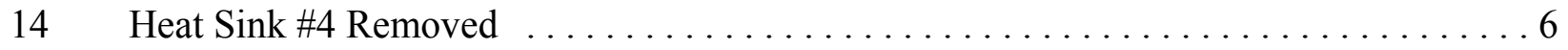

15 Burned Spot on the Heat Exchanger Created by Thermocouple Short $\ldots \ldots \ldots \ldots$

16 Thermoelectric Module \#3 from the Array \#4 Damaged by Thermocouple

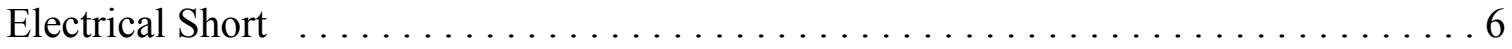

17 Thermoelectric Array After Durability Test $\ldots \ldots \ldots \ldots \ldots \ldots \ldots \ldots \ldots \ldots \ldots \ldots \ldots \ldots$

18 Thermal Interface Material Evaluation Hot/Cold Sides Temperature Differentials . . . 8

19 Shock Absorption System before Test . . . . . . . . . . . . . . . . 8

20 Shock Absorption System After Test $\ldots \ldots \ldots \ldots \ldots \ldots \ldots \ldots \ldots \ldots$

21 Quantum Well Thermoelectric Couple on $5 \mu \mathrm{m} \mathrm{Si} \ldots \ldots \ldots \ldots \ldots \ldots \ldots$ 


\section{List of Figures (Continued)}

22 Efficiency of QW Couple vs Film Thickness on a $5 \mu \mathrm{m}$ Si Substrate . . . . . . . . . 10

23 QW Si/SiGe-B ${ }_{4} \mathrm{C} / \mathrm{B}_{9} \mathrm{C}$ Couple for Thermal Stability Test with Mo Contact . . . . . . . 11

24 Mock up of $21 / 2$ Watt Quantum Well Module $\ldots \ldots \ldots \ldots \ldots \ldots \ldots \ldots$

25 Overall view of Electron-Beam-Heated Deposition System . . . . . . . . . . . . . 12

26 Source, Hot-Wall, Substrate Holder and Shutter . . . . . . . . . . . . . . . . 12

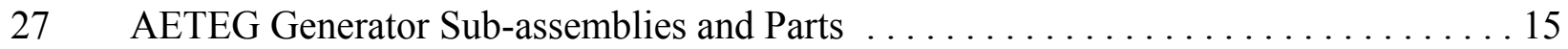

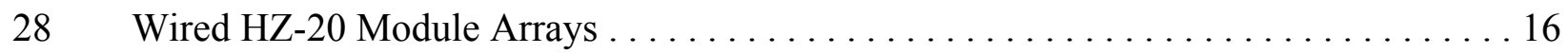

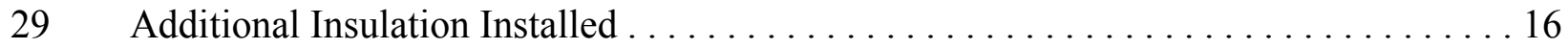

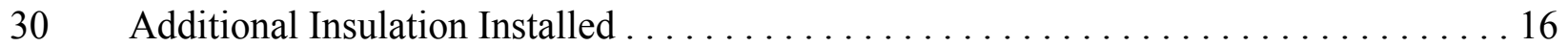

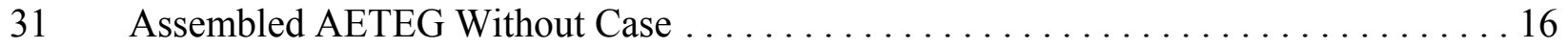

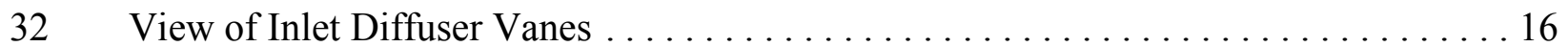

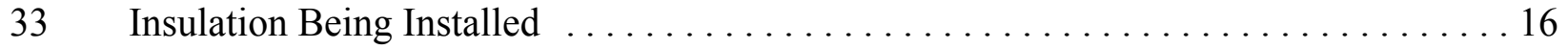

34 AETEG Connected to Air Heater . . . . . . . . . . . . . . . . . . . . . . . . . 17

35 Power Conditioning Unit (PCU) Bench Test $\ldots \ldots \ldots \ldots \ldots \ldots \ldots \ldots \ldots \ldots$

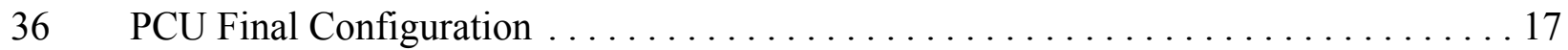

37 Photograph of a 300 Watt Generator Mounted Beneath Truck . . . . . . . . . . . . 17

$38 \quad 200 \mathrm{~W}$ TEG for Hybrid Elecric Vehicle Underassembly $\ldots \ldots \ldots \ldots \ldots \ldots \ldots$

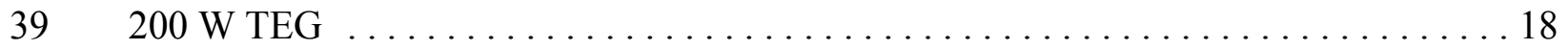

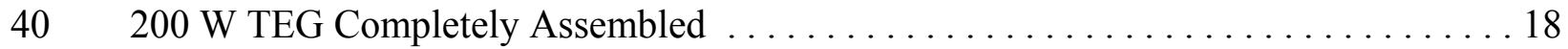

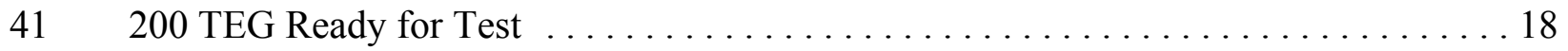

$42 \quad 200$ W TEG Hot Air Blower Test 18

$43200 \mathrm{~W}$ TEG Power Managment System $\ldots \ldots \ldots \ldots \ldots \ldots \ldots \ldots \ldots \ldots \ldots$ 


\section{List of Figures (Continued)}

44 Interchangeable Integrated QW Thermoelectric Unit $\ldots \ldots \ldots \ldots \ldots \ldots \ldots$

45 Interchangeable Integrated QW Thermoelectric generator $\ldots \ldots \ldots \ldots \ldots$

46 Thermal Conductivity of $\mathrm{P}$ Leg $\mathrm{B}_{4} \mathrm{C} / \mathrm{B}_{9} \mathrm{C}$ QW Composite and Si Substrate

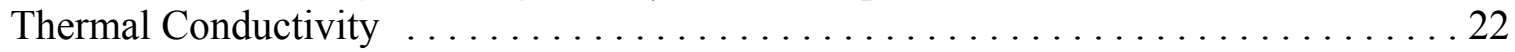

$47 \mathrm{Si} / \mathrm{SiGe}$ and $\mathrm{B}_{4} \mathrm{C} / \mathrm{B}_{9} \mathrm{C} \mathrm{QW}$ Module Efficiency $\ldots \ldots \ldots \ldots \ldots \ldots \ldots \ldots \ldots \ldots$

$48 \quad \mathrm{~N}$-Type $\mathrm{Si} / \mathrm{SiGe}$ P-type $\mathrm{B}_{4} \mathrm{C} / \mathrm{B}_{9} \mathrm{C}$ QW TE Heat Flux $\ldots \ldots \ldots \ldots \ldots \ldots \ldots \ldots \ldots$

49 Temperature Across Two Different TE Modules in Various Hot and Cold

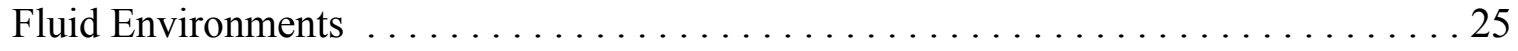

50 Portion of $5 \mathrm{kWe}$ QW Thermoelectric Generator Showing One Row of Quantum Well Thermoelectric Modules Surrounding Waste Heat Stream . . . . . . . . . 26

51 Waste Heat Recovery Thermoelectric Generator With Quantum Well

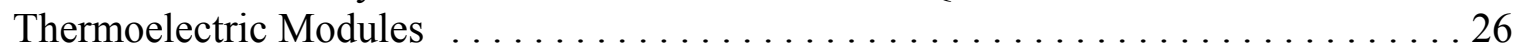

52 Section Through One Quantum Well Module Showing N and P Legs, Coolant Heat

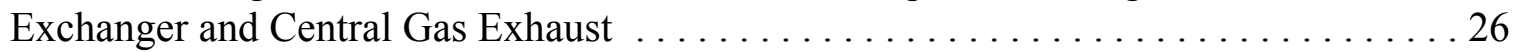

\section{List of Tables}

1 List of the Candidates for Interface Material Tested at Hi-Z $\ldots \ldots \ldots \ldots \ldots \ldots$

2 Summary of Measured Composition of Thin Films $\ldots \ldots \ldots \ldots \ldots \ldots \ldots$

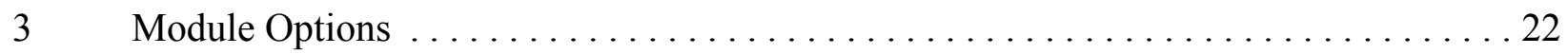




\section{EXECUTIVE SUMMARY}

Hi-Z Technology, Inc. (Hi-Z) is currently developing four different auxiliary generator designs that are used to convert a portion ( 5 to $20 \%$ ) of the waste heat from vehicle engines exhaust directly to electricity. The four designs range from 200 Watts to $10 \mathrm{~kW}$. The furthest along is the $1 \mathrm{~kW}$ Diesel Truck Thermoelectric Generator (DTTEG) for heavy duty Class 8 Diesel trucks, which, under this program, has been subjected to 543,000 equivalent miles of bouncing and jarring on PACCAR's test track. Test experience on an earlier version of the DTTEG on the same track showed the need for design modifications incorporated in DTTEG Mod 2, such as a heavy duty shock mounting system and reinforcement of the electrical leads mounting system, the thermocouple mounting system and the thermoelectric module restraints. The conclusion of the 543,000 mile test also pointed the way for an upgrading to heavy duty hose or flex connections for the internal coolant connections for the TEG, and consideration of a separate lower temperature cooling loop with its own radiator. Fuel savings of up to $\$ 750$ per year and a three to five year payback are believed to be possible with the $5 \%$ efficiency modules. The economics are expected to improve considerably to approach a two year payback when the $5 \mathrm{~kW}$ to $10 \mathrm{~kW}$ generators make it to the market in a few years with a higher efficiency (20\%) thermoelectric module system called Quantum Wells, which are currently under development by Hi-Z. Ultimately, as automation takes over to reduce material and labor costs in the high volume production of QW modules, a one year payback for the $5 \mathrm{~kW}$ to $10 \mathrm{~kW}$ generator appears possible. This was one of the stated goals at the beginning of the project. At some future point in time, with the DTTEG becoming standard equipment on all trucks and automobiles, fuel savings from the $25 \%$ conversion of exhaust heat to useable electricity nationwide equates to a $10 \%$ reduction in the 12 to 15 million barrels per day of imported oil, that much less air pollution, and an equivalent reduction in the trade deficit, which is expected to lower the inflation rate.

\section{COMPARISON OF ACTUAL ACCOMPLISHMENTS WITH OBJECTIVES}

The objective was to develop a $1 \mathrm{~kW}$ thermoelectric generator (TEG) for Diesel Trucks that could save enough fuel through energy recovery from the exhaust waste heat conversion system to pay for itself in one year. To do this, Quantum Well (QW) technology would have to be advanced to commercial status to achieve the $20 \%$ recovery needed to make the economics work. The ruggedness of the DTTEG design has been demonstrated with bulk material Bismuth Telluride modules which have a nominal efficiency of 5\%. Development of QW technology, which offers the potential of 20 to $30 \%$ efficiency, is a work in progress. Several QW couples have been built and tested, and the resultant efficiency is right on the predicted curve. QW Module design for a $21 / 2 \mathrm{~W}$ module is in progress. To bring Quantum Well modules to the 55 to 80 Watt rating needed in the TEG requires three or four more years development, represented by the Army's TACOM $10 \mathrm{~kW}$ Underarmor Generator project. This is a natural follow on to the $1 \mathrm{~kW}$ DTTEG project. All of the design data generated in the DTTEG project has been transferrable to the TACOM project, and has resulted in a conceptual design involving $64 \mathrm{QW}$ modules of 80 Watt power rating in each of the two $5 \mathrm{~kW}$ generators mounted thermally in series beneath the armor of the Stryker vehicle. For comparison, 72 of the Bismuth Telluride modules of 14 Watt power rating were used in the $1 \mathrm{~kW}$ DTTEG. 
To advance the Quantum Well Film and Module development, Hi-Z placed a purchase order for a 34" ID "next generation" sputtering machine on December 1, 2003, with funding split among this project and three additional active government projects. This machine has passed target sputtering shop trials at AJA International's facility. The shop trials uncovered the need for a specialized power supply unit which had to be back ordered. The 34 " machine has been shop tested with the new power supply and has passed the tests. With the installation of the 34" machine, Hi-Z's capacity to make QW film is increased by a factor of 100 to 200. Also, to increase availability of QW film, a purchase order was placed with Pacific Northwest National Laboratory (PNNL) to supply eighteen 4" diameter wafers of multilayer B4C/B9C and $\mathrm{Si} / \mathrm{SiGe} 11$ microns thick on a Silicon substrate. The initial shipment of wafers is being evaluated by Hi-Z. Further, to evaluate faster ways of producing QW film, an Electron Beam Hot Wall Apparatus was designed, built and started up by Hi-Z. Initial material shows promise of being in the right compositional range, but it is too early to test for Quantum Well properties. Lastly, under QW development, a method of joining $\mathrm{N}$ and $\mathrm{P} \mathrm{QW}$ legs by laser assisted sputtering with Molybdenum has given good results, clearing the way for higher temperature evaluation of the QW couples.

Another objective was to advance the overall TEG development program by providing support (both technical and financial) to the Clarkson/NYSERDA project in the development of the 300 Watt Automobile Exhaust Thermoelectric Generator (AETEG) for the Chevrolet Sierra pickup truck. The AETEG has passed the field trial stage with the automated Power $\underline{\text { Operating }} \underline{\text { Maintenance }} \underline{\text { System }}$ (POMS), and is ready for the next phases, involving design refinements, value engineering and planning for commercialization. In a parallel program with Ohio State for the development of a 200 Watt Light Truck Exhaust Thermoelectric Generator (LTETEG), financial and technical assistance was provided to refurbish an existing TEG, outfit it with eighteen 14 Watt modules (HZ-14) and subject it to the hot air blower testing. The unit was shipped to Ohio State for the Hybrid Vehicle (Chevrolet Suburban) under the Future Truck Program.

\section{SUMMARY OF PROJECT ACTIVITIES}

\section{3-A. DTTEG DEVELOPMENT WITH BULK MATERIAL T/E MODULES}

The $1 \mathrm{~kW}$ TEG prototype previously demonstrated under DOE and California Energy Commission funding was dismantled, refurbished and reassembled with 72 upgraded high aluminum density HZ14 bulk material Bismuth telluride modules. Figures 1, 2 and 3 show the DTTEG in various stages of reassembly. After testing in Hi-Z's shop on the hot air blower system with $500^{\circ} \mathrm{C}$ exhaust at one twentieth of the truck exhaust flow to prove integrity (Figure 4), the DTTEG was shipped to the NGen Corporate Facility in Stanton, CA for testing on a 14 liter Cummins Diesel Engine in a test cell. Figure 5 shows the DTTEG undergoing testing in the test cell. It was found that TEG power output strongly depends on engine loading and less on the engine speed as illustrated in Figure 6.

The DTTEG was shipped to PACCAR's test track facility in Mount Vernon, Washington, where it was mounted on a Kenworth Class 8 Diesel truck, as shown on Figures 7, 8, 9 and 10. The test track has inclines, potholes, ruts and bumps to give the vehicles and their contents a severe accelerated mechanical road test. One mile on the test track is equivalent to 150 miles on typical roads and highways. 


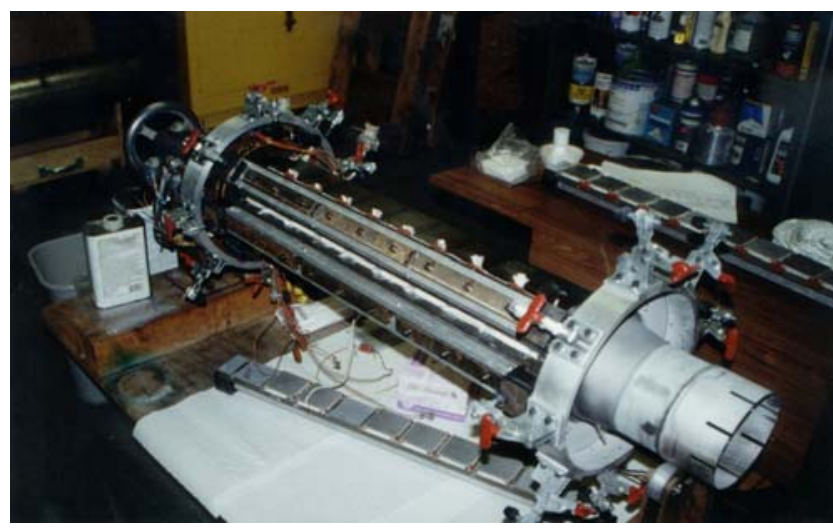

Figure 1. TEG Under Assembly. Heat Exchanger with Two Heat Sinks.

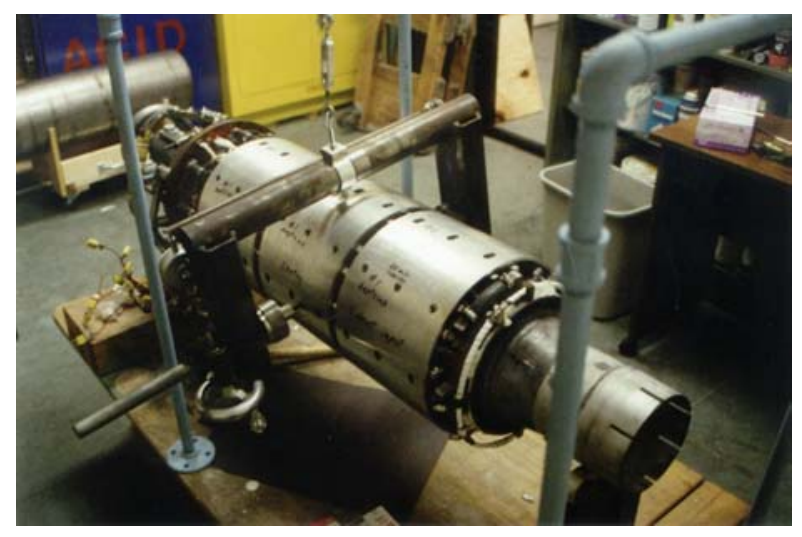

Figure 3. Applying Pressure to the Heat Sink

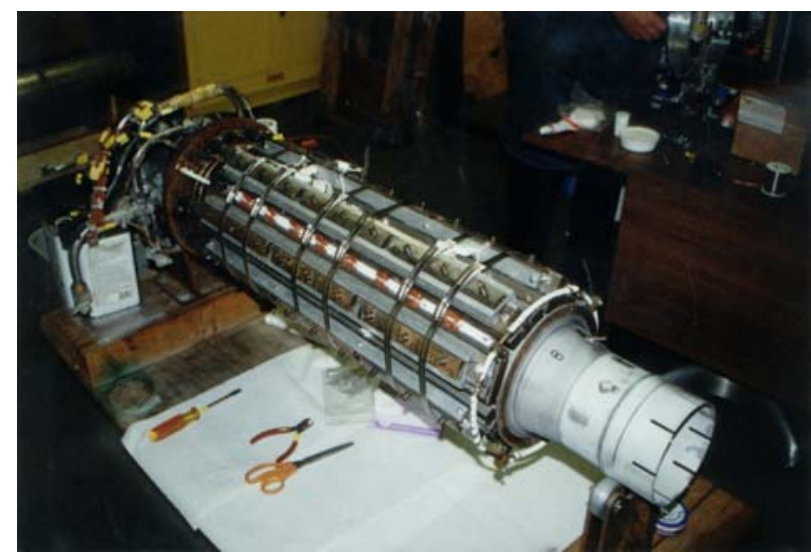

Figure 2. TEG Heat Exchanger with all TE Modules, Electrical Wiring and Heat Sinks

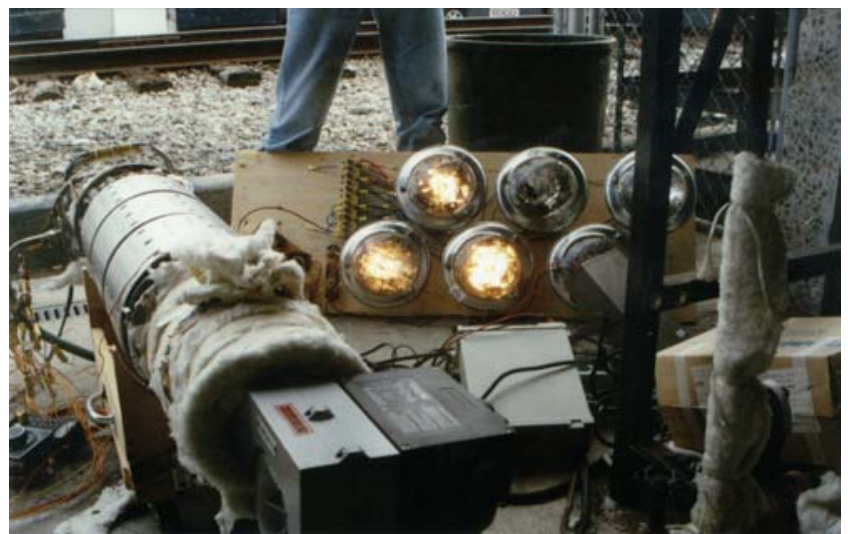

Figure 4. $1 \mathrm{~kW}$ TEG Test with Hot Air Blower. Light bulb loading board for obtaining matched load.

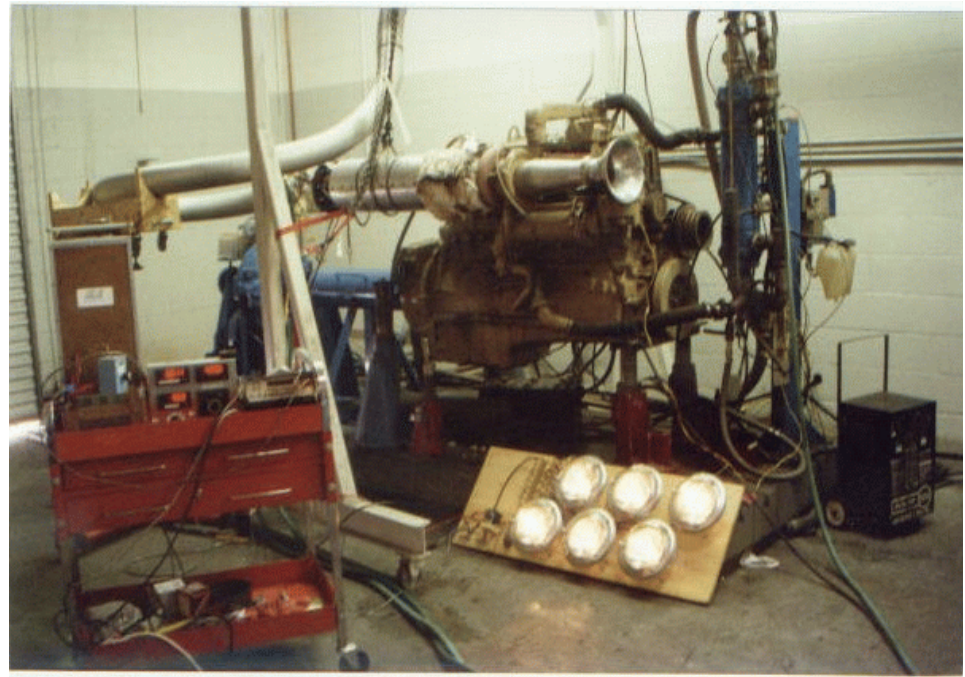

Figure 5. 1 kW TEG In-cell Test. Electronic loading device and light bulb load operate simultaneously to obtain matched load 


\section{TEG Power, $\mathbf{W}$}

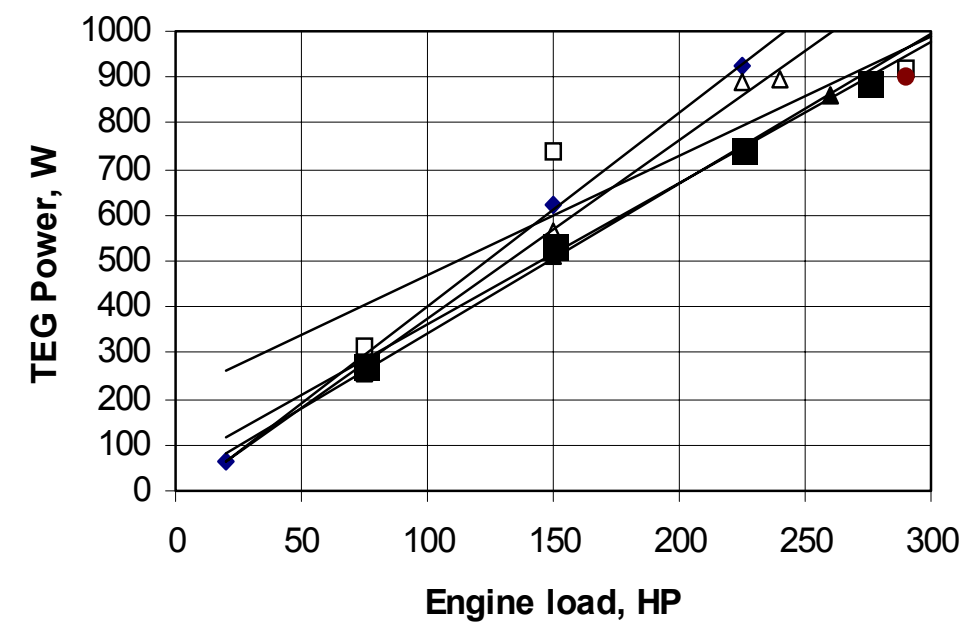

- 1300 RPM

$\triangle 1500 \mathrm{RPM}$

\ $1700 \mathrm{RPM}$

1900 RPM

2100 RPM

- 2200 RPM

Figure 6. TEG Power Output as a Function of the Engine Load and Speed
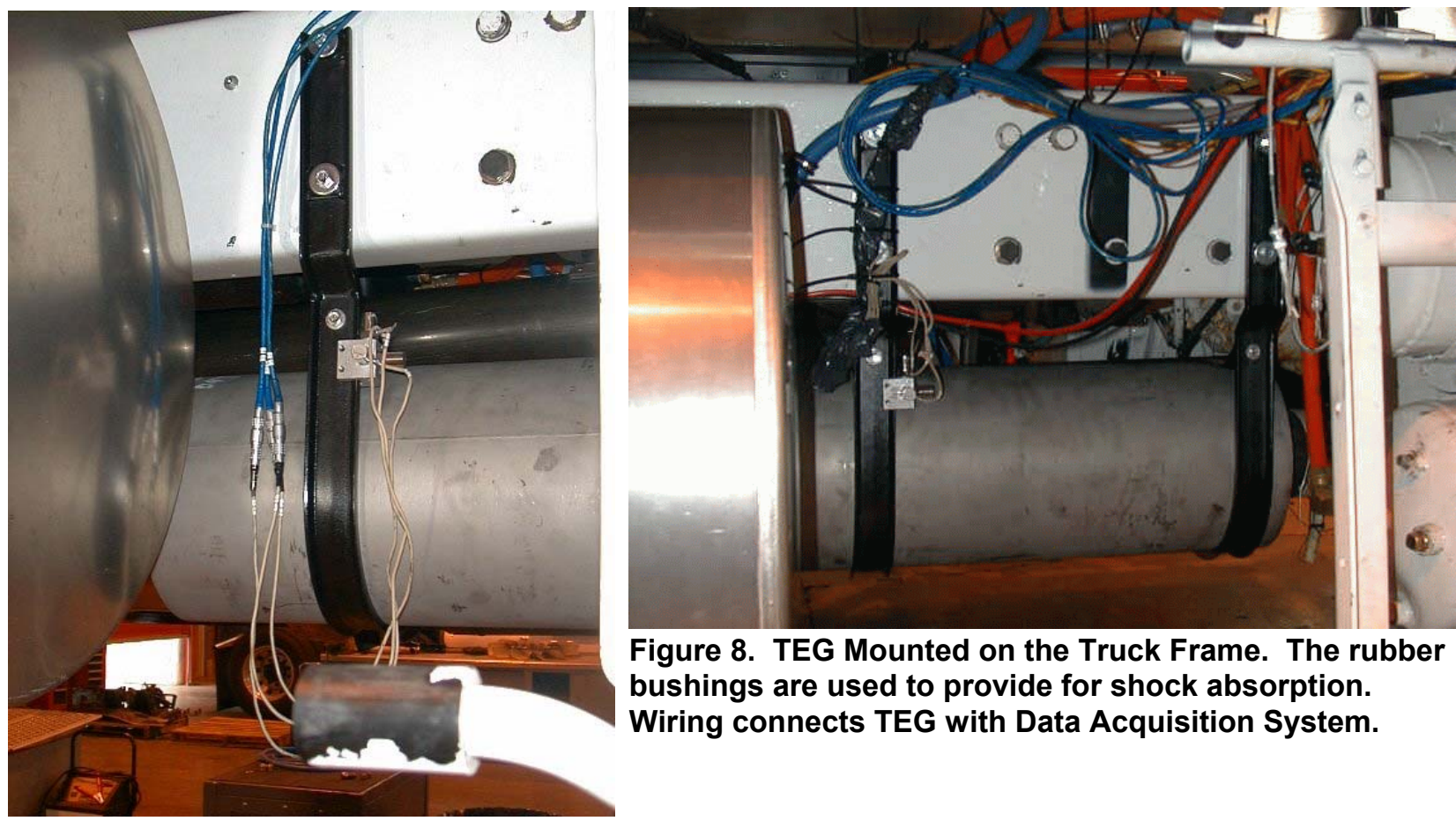

Figure 8. TEG Mounted on the Truck Frame. The rubber bushings are used to provide for shock absorption. Wiring connects TEG with Data Acquisition System.

Figure 7 - TEG Mounted on the Truck Frame with Shock Absorption Bracket. Three accelerometers are connected with the Data Acquisition System. 


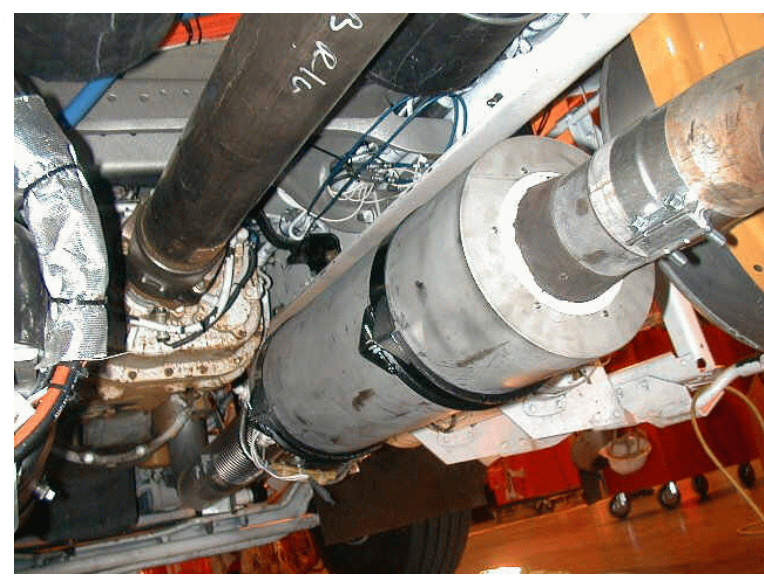

Figure 9. TEG Mounted on the Truck, View From the Bottom

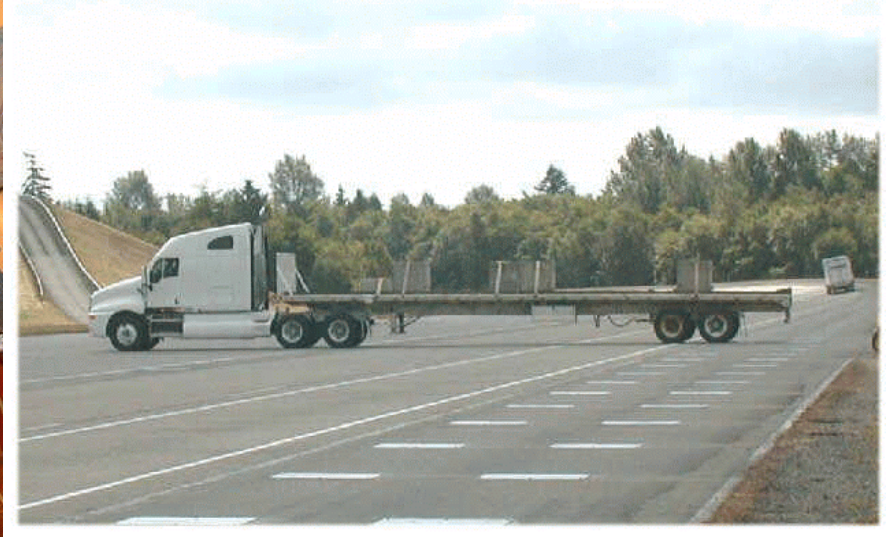

Figure 10. Kenworth Class Eight Diesel Truck With Integrated TEG (under the cabin) on PACCAR's 150 to 1 Test Road. Speed Bumps and Hill Section.

Instruments were hooked up to the DTTEG aboard the truck to give continuous indication of performance and stress. After 55,000 equivalent test miles, the DTTEG output voltage dropped to zero. It was removed and shipped back to Hi-Z for dismantlement and inspection. It was discovered that the thermocouples had been jarred loose and caused internal shorts, porcelain insulators were cracked and separated, two power leads were severed, and one module was dislocated and failed. Figures 11, 12, 13, 14, 15, 16 and 17 show the extent of the internal damage. The unit was redesigned and rebuilt twice to correct the deficiencies. An investigation into potential replacement for the fragile porcelain insulators revealed that after all was considered, the porcelain insulators were the best available for their assigned interface job. Table 1 and Figure 18 showed the extent of the investigation into alternate insulator material. Tests were then performed on the rebuilt TEG in Hi-Z's shops to demonstrate electrical and physical integrity at room temperature and at gas temperatures of $500^{\circ} \mathrm{C}$. When we were satisfied that we had a more rugged design, the DTTEG (now labeled as TEG Mod 2) was shipped back to PACCAR for more road testing.

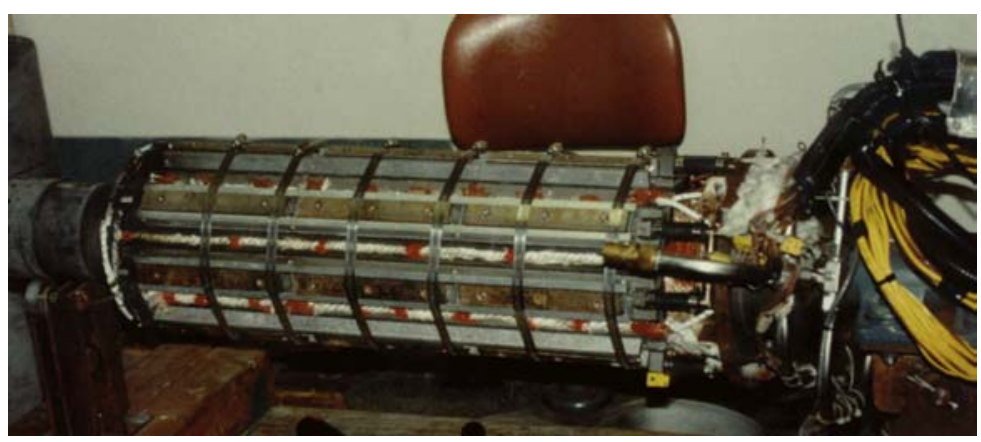

Figure 11. TEG After Durability Test (55,000 miles). Outer shell removed.

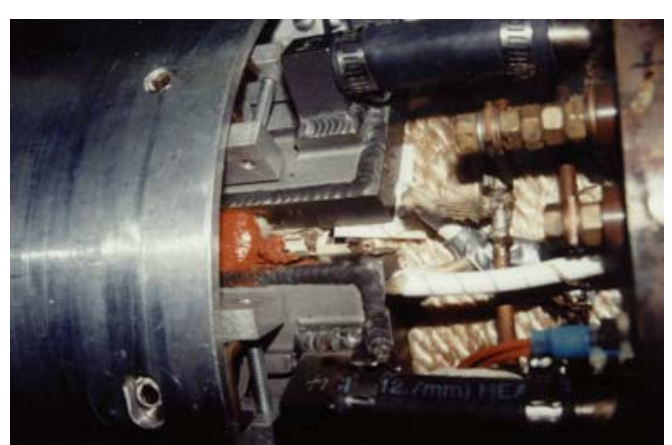

Figure 12. Disconnected Leads. TE Module \#9, Array \#4 partially moved from original position. Ceramic wafer partially moved from the place. 


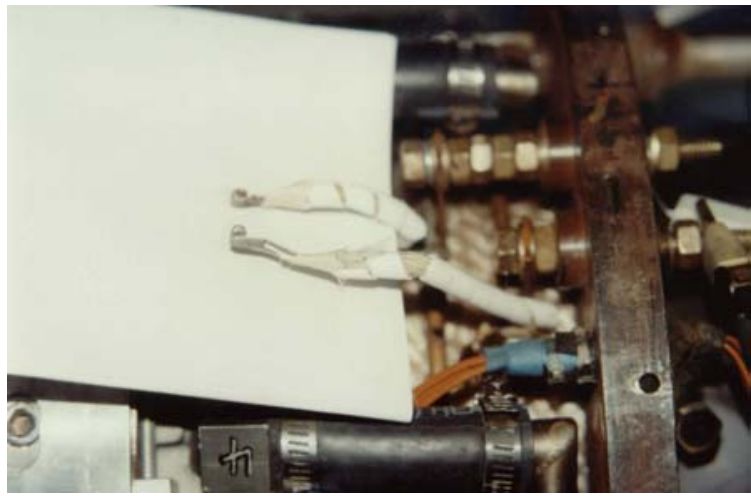

Figure 13. Disconnected Leads. Close-up.

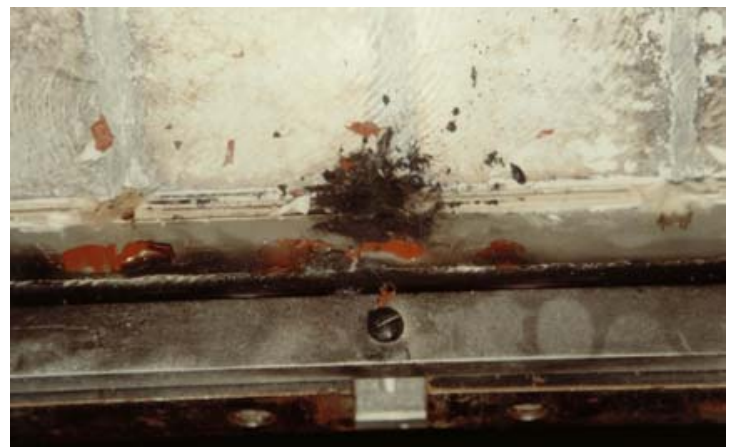

Figure 15. Burned Spot on the Heat Exchanger Created by Thermocouple Short.

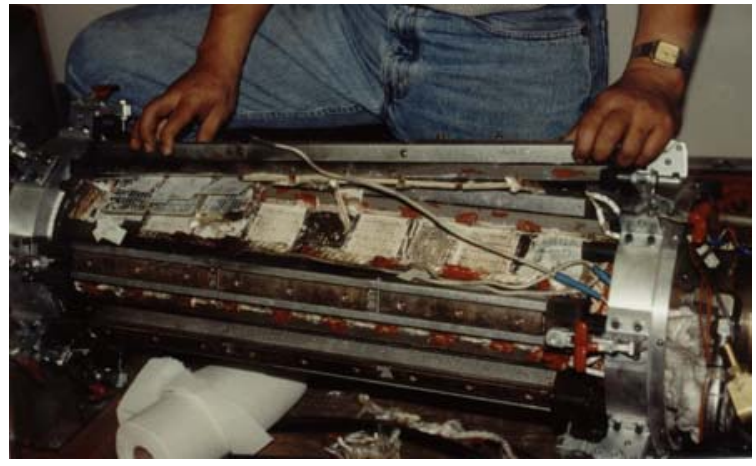

Figure 14. Heat Sink \#4 Removed. Thermocouple wires exposed.

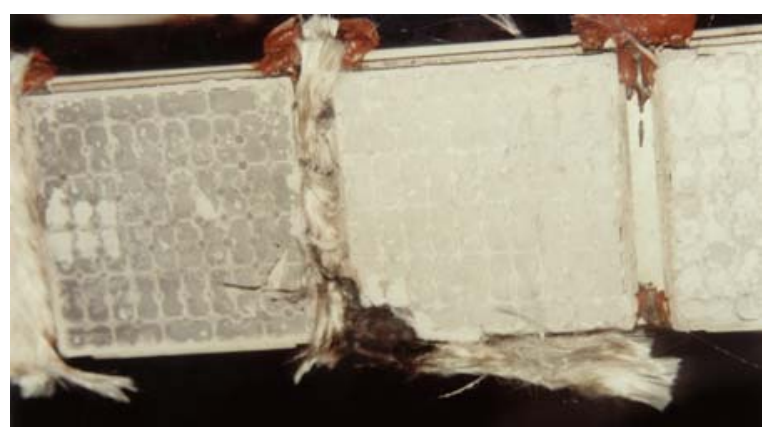

Figure 16. Thermoelectric Module \#3 from the Array \#4 Damaged by Thermocouple Electrical Short

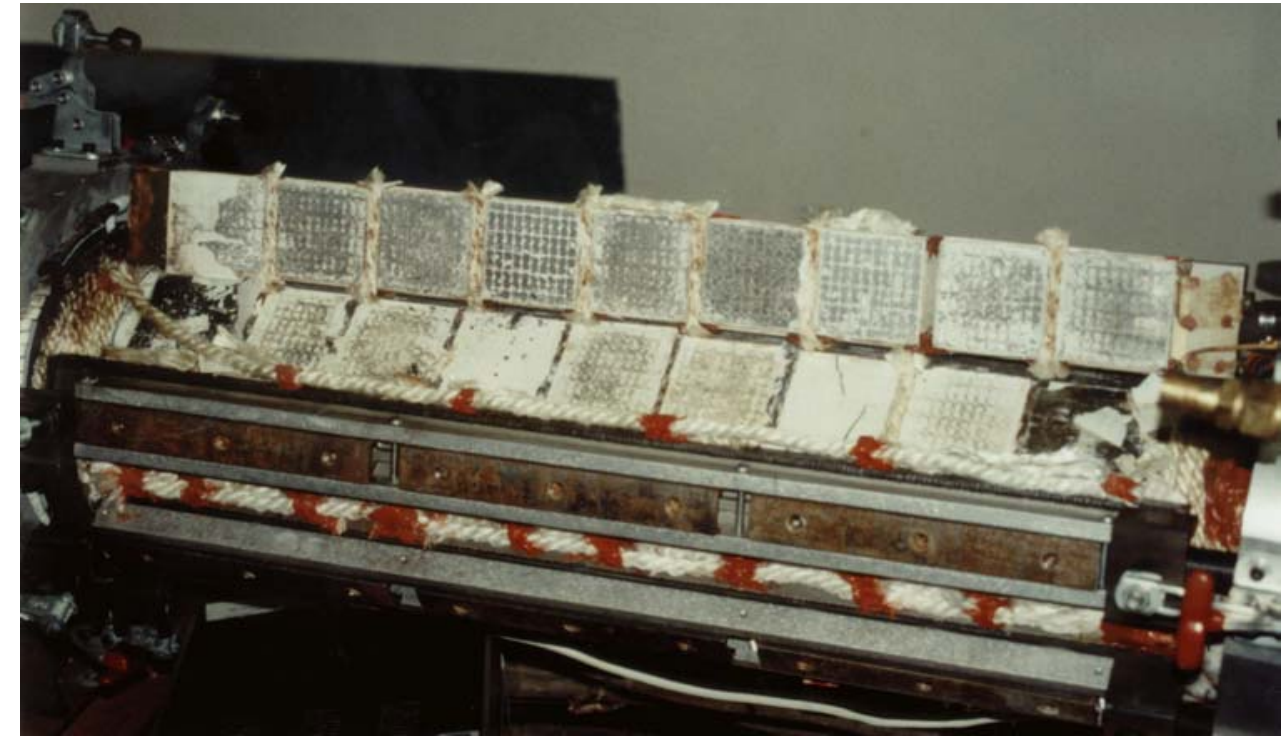

Figure 17 - Thermoelectric Array after Durability Test. All the modules, ceramic wafers, soft insulation, RTV in place. 
Table 1. List of the Candidates for Interface Material Tested at Hi-Z

\begin{tabular}{|c|c|c|c|c|}
\hline & Material & Manufacturer & ) T@ 300 w & Cost \\
\hline 1 & Alumina, 0.010 in. thick & DuPont & 5 & $\$ 28 / \mathrm{ft}^{2}$ \\
\hline 2 & Kapton ${ }^{\circledR}, 0.001$ in. thick, one layer & DuPont & 9 & \\
\hline 3 & Kapton $®$, MT, 0.001 in. thick, two layers & DuPont & 14 & \\
\hline 4 & 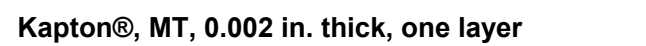 & DuPont & 13 & $\$ 3.62 / \mathrm{ft}^{2}$ \\
\hline 5 & Kapton ${ }^{\circledR}, \mathrm{MT}, 0.003$ in. thick, one layer & DuPont & 16 & \\
\hline 6 & Polarchip ${ }^{\mathrm{TM}}$ CP7003-040, 0 .040in. Thick & W.L. Gore \& Associates & & \\
\hline 7 & Nextel $^{\mathrm{TM}} 610$ 1500D 8HX XN 474, 0.008 in. thick & $3 \mathrm{M}$ & 14 & $\$ 52 / \mathrm{ft}^{2}$ \\
\hline 8 & Nextel ${ }^{\mathrm{TM}} 312 \mathrm{AF} 12,0.009$ in. thick & $3 \mathrm{M}$ & & \\
\hline 9 & Nextel $^{\text {TM }} 312$ Dot Paper $70-80 \mathrm{~g} / \mathrm{m}^{2}, 0.012$ in. thick & $3 \mathrm{M}$ & & \\
\hline 10 & Nextel $^{\mathrm{TM}} 312 \mathrm{AF}-8$, Linoweave 0.0125 in. thick & $3 \mathrm{M}$ & & \\
\hline 11 & Isostrate (Phase change), 0.003 in. thick & Power Devices, Inc. & & \\
\hline 12 & Natural Mica, 0.004 in. thick & & & \\
\hline 13 & Synthetic Mica Film, 0.0015 in. thick & Crystalsland & 13 & \\
\hline 14 & Synthetic Mica Sheet, 0.01 in. thick & Crystalsland & & \\
\hline 15 & Synthetic Mica Paper, 0.0035 in. thick & Crystalsland & & \\
\hline 16 & HP5 Silicon Bonded Mica Paper, 0.006 in. thick & Asheville & & \\
\hline 17 & HP5 Silicon Bonded Mica Sheet, 0.0095 in. thick & Asheville & & \\
\hline 18 & 797 Mica Paper 2SM2, 0.0025 in. thick & US Samica & 19 & \\
\hline 19 & Laminate Strip Tape, 0.0025 in. thick & US Samica & 16 & \\
\hline 20 & CeQuin ${ }^{\circledR}$ I Inorganic Paper, 0.005 in. thick & Quin-T Corp & & \\
\hline 21 & Nextel $^{\mathrm{TM}} 6101500 \mathrm{D} 8 \mathrm{HX}$ XN 694, 0.008 in. thick & $3 \mathrm{M}$ & 13 & \\
\hline 22 & Boron Nitride plate BIN77, 0.010in. Thick & Advanced Ceramics & 6 & $\$ 507 / \mathrm{ft}^{2}$ \\
\hline 23 & Kapton ${ }^{\circledR}, \mathrm{CR} 0.002$ in. thick, one layer & DuPont & 16 & $\$ 4.20 / \mathrm{ft}^{2}$ \\
\hline 24 & Kapton®, HM 0.002 in. thick, one layer & DuPont & 26 & \\
\hline 25 & Copper, 1-2 mil/alumina, 15 mil, pattern & Cirqon & 6 & \\
\hline 26 & Copper, 5 milAl $_{2} \mathrm{O}_{3}, 25$ mil, BDC & Alberox & 7 & \\
\hline 27 & Copper, $5 \mathrm{~m}$ il/AIN, 25 mil, DBC & Alberox & 4 & \\
\hline 28 & Sarcon XR-HE, 22.5 mil, silicon gap filler & Fujipoly & 32 & \\
\hline 29 & Sil Pad, 9.5 mil & Berquist & 10 & \\
\hline 30 & DBC, Copper, $5 \mathrm{mil} / \mathrm{Al}_{2} \mathrm{O}_{3}, 12 \mathrm{mil}, 2 \times 2 \times 0.12$ & Stellar & & \\
\hline 31 & $\mathrm{DBC}$, Copper, $3 \mathrm{mil} / \mathrm{Al}_{2} \mathrm{O}_{3}, 25 \mathrm{mil}$ & Dynamic Hidrid & & \\
\hline
\end{tabular}




\section{Delta T vs. T hot Interface Materials}

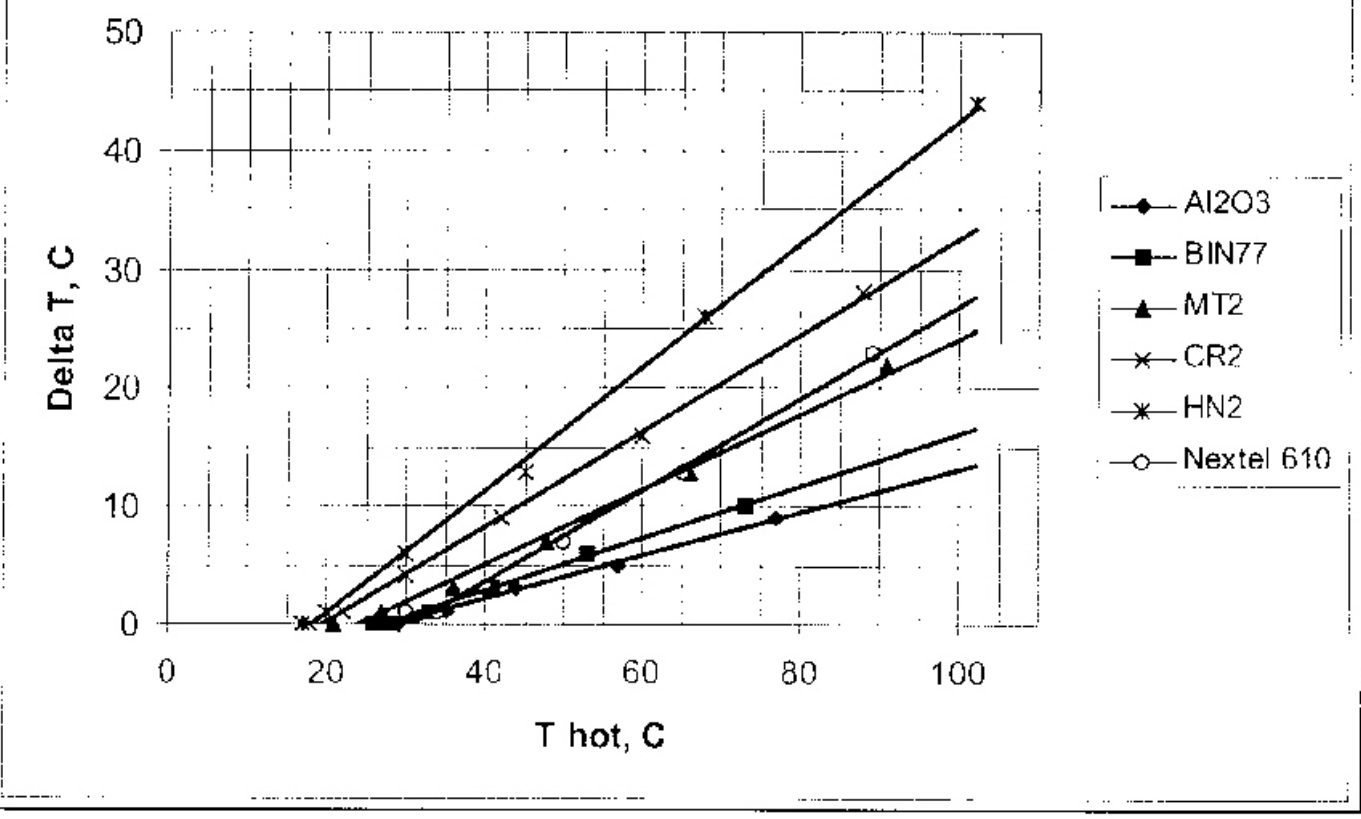

Figure 18. Thermal Interface Material Evaluation Hot/Cold Sides Temperature Differentials

At some point, after about 70,000 additional equivalent miles, the earliest version of the vibration isolators installed on the Kenworth truck for the DTTEG mounting failed and caused concern for the physical integrity of the TEG, so it was shipped back to Hi-Z for inspection. There, a resistivity test performed externally on the TEG revealed that it was still within specifications, so it was shipped back to PACCAR, along with a duplicate set of instruments that Hi-Z recommended for future external checks at PACCAR. After another 68,000 miles, or 190,000 total cumulative miles, the new steel cable vibration isolators failed (See Figures 19 and 20).

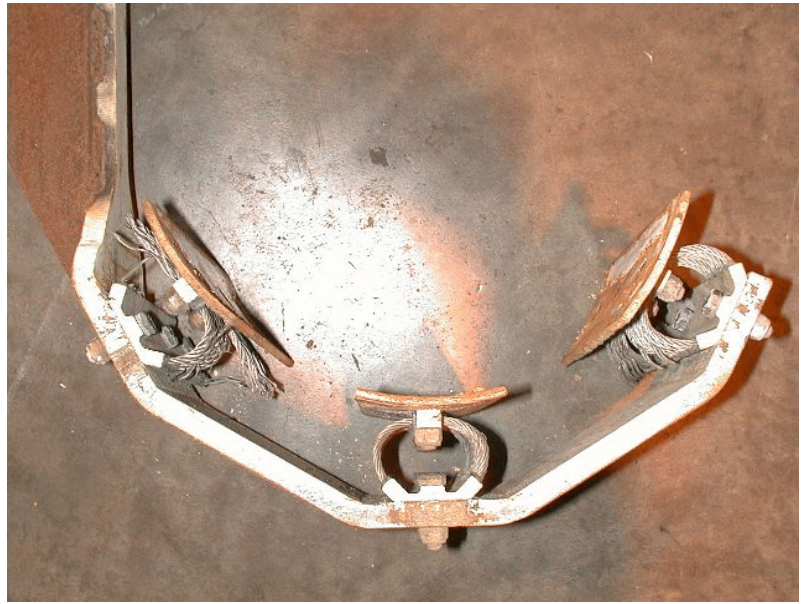

Figure 19. Shock Absorption System Before Test

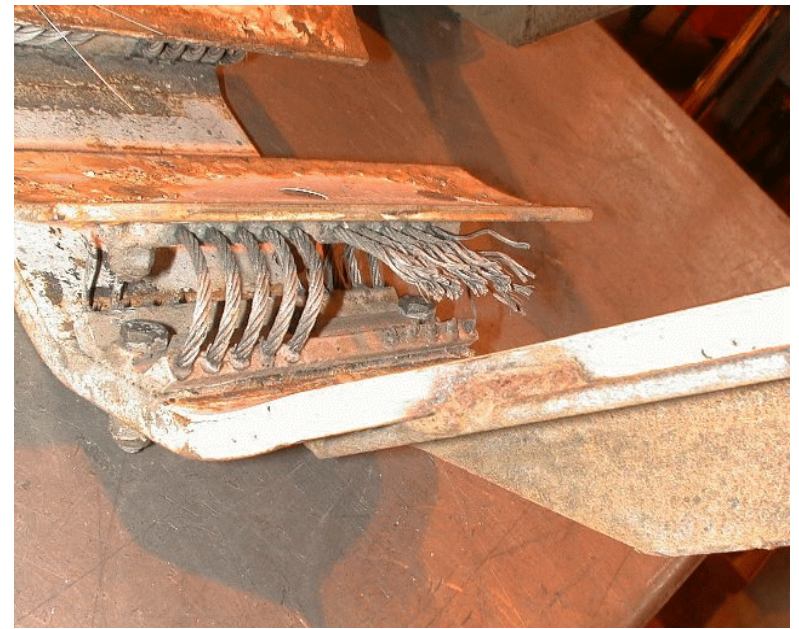

Figure 20. Shock Absorption System After Test 
The ensuing runs at PACCAR, which brought the total cumulative equivalent miles to over 543,000 on TEG Mod 2, were run with high temperature coolant, with no exhaust gas entering the DTTEG, to prove out the durability to shock and vibration from the road, with new improved vibration isolators. Since previous failures were attributed to the transmission of unacceptable levels of shock and vibration through the vibration isolators, PACCAR and $\mathrm{Hi}-\mathrm{Z}$ felt comfortable with this direction of the testing. The culmination of the road testing at 543,000 cumulative equivalent miles came through failure of the coolant hoses within the DTTEG, attributable to long term exposure of the hoses to high temperature coolant, not to shock or vibration.

Several conclusions can be reached:

1. Advanced vibration isolators for the truck mounting connection are critical to success and long life.

2. The enhancements to the TEG Mod 1 design to produce Mod 2 were successful. No internal shorting was experienced after this. Further mechanical enhancements will be studied during pre-commercial preparations.

3. The $1 \mathrm{~kW}$ nominal rating can be produced at favorable times in engine performance, and in static tests in the test cell, but there are times in the road cycle when the engine is not fully loaded that will produce much less power. If this coincides with less electrical demand for the truck, then this is acceptable. Further work needs to be done in this area to determine if the electrical load for pollution abatement and auxiliaries indeed tapers off at these points.

4. A separate cooling loop that can supply lower temperature cooling water to the DTTEG needs to be explored as a means of maintaining a higher delta $T$ across the thermoelectric modules. The TEG produced $528 \mathrm{~W}$ of electrical power on PACCAR's road test with engine coolant at $90^{\circ} \mathrm{C}$. In the test cell, $22^{\circ} \mathrm{C}$ city water produced $1 \mathrm{~kW}$ of electric power from the TEG. Future programs will determine how close the separate cooling loop can get to the range of 30 to $50^{\circ} \mathrm{C}$. Increasing the ) $\mathrm{T}$ by $50^{\circ} \mathrm{C}$ almost doubles the power output.

5. Higher strength, longer endurance coolant hoses or flex connections need to be incorporated into the DTTEG during design to prevent premature coolant system failure during expected life of the unit.

6. Soot deposits found inside the part of the DTTEG core exposed to exhaust gases reduced performance by about $10 \%$. Sand blasting of the core restored its performance to almost new conditions. With the additional exhaust gas cleanup equipment projected to be powered by the extra power supplied by the DTTEG, this potential problem may disappear with time. Future programs will address this.

7. Interim use of improved bulk material modules of optimized doped material may cause a slight improvement in performance, but the long term goals can only be met 
with QW modules that will exhibit 4 to 5 times the efficiency converting waste heat to electricity.

\section{3-B QUANTUM WELL DEVELOPMENT BY SPUTTERING}

An efficiency of $14 \%$ has been measured on a couple that combined a multilayer QW of $\mathrm{P}$ type $\mathrm{B}_{4} \mathrm{C} / \mathrm{B}_{9} \mathrm{C}$ with a $\mathrm{QW}$ of $\mathrm{Si} / \mathrm{SiGe}$, shown in Figure 21. This couple operated between $70^{\circ} \mathrm{C}$ and $250^{\circ} \mathrm{C}$ and was fabricated on a 5 micron thick $\mathrm{Si}$ substrate with 11 micron thick QW's. The efficiency was calculated by dividing the electric power out of the couple by the electric power into the heater. A $14 \%$ efficiency was obtained with no correction for any extraneous heat losses, such as through the silicon substrate and the heater wires. The experimental setup also confirmed a known efficiency around $5.5 \%$ for presently used Bismuth Telluride bulk material modules. The $14 \%$ data point and the predicted

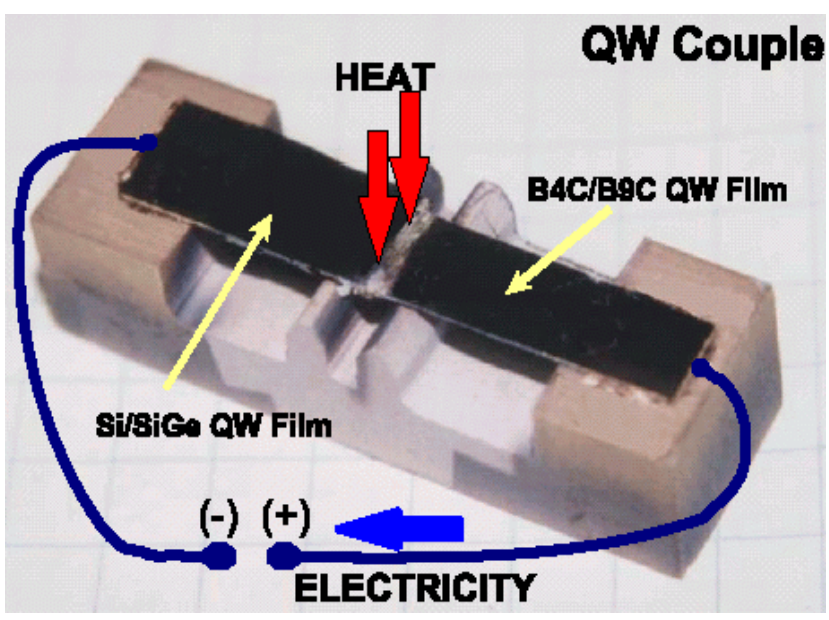

Figure 21. Quantum Well Thermoelectric Couple on $5 \mu \mathrm{m} \mathrm{Si}$ values agree very well as shown in Figure 22. In another separate confirming experiment, at a lower temperature, the $\mathrm{B}_{4} \mathrm{C} / \mathrm{B}_{9} \mathrm{C}$ film was used as a cooler creating a maximum difference of $45^{\circ} \mathrm{C}$.

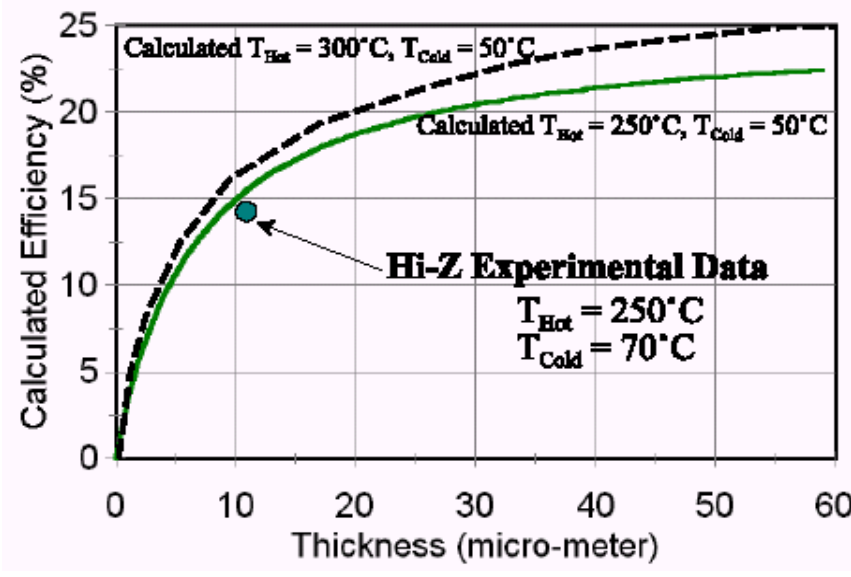

Figure 22. Efficiency of QW Couple vs Film Thickness on a $5 \mu \mathrm{m}$ Si Substrate. Hi-Z experimental and predicted values are shown for comparison for $\mathrm{N}$ type Si/SiGe and $\mathrm{P}$ type $\mathrm{B}_{4} \mathrm{C} / \mathrm{B}_{9} \mathrm{C}$.
In another strategic experimental area, good progress has been made in increasing the high temperature strength and decreasing the resistance of the joint where $\mathrm{N}$ and $\mathrm{P}$ couples are joined together. The use of laser assisted sputtering of Molybdenum at the interface proved to be superior to earlier joints of epoxy and conductive inks and pastes. The problem at the joint is that 1100 layers of 100 Angstrom thick alternating different electron band gap film materials each need to be wetted by the conductive joint material. Failure to do so results in abnormally high resistivity which adversely impacts the QW joint performance and potentially the module performance.

Hi-Z's current laboratory sized 18" sputtering machine produces a one square inch QW film 11 microns in thickness in over 200 hours of operation. The new fully automated 34 " sputtering machine is projected to be capable of producing 300 square inches of 11 micron film within the same 200 hour period. The 34" machine installation is scheduled for early January, 2005. It has been checked out for target sputtering in the vendor's shop, and has passed the test. The specialized 
power supply was back ordered and passed recent shop tests on target sputtering. In the interim, PNNL has been contracted to supply eighteen 4 " diameter wafers of multilayer $\mathrm{B}_{4} \mathrm{C} / \mathrm{B}_{9} \mathrm{C}$ and $\mathrm{Si} / \mathrm{SiGe}$ 11 microns thick on a Silicon substrate produced by sputtering. The initial shipment of eleven wafers is being evaluated by Hi-Z.

Figure 23 shows a new QW couple with $\mathrm{B}_{4} \mathrm{C} / \mathrm{B}_{9} \mathrm{C}$ and $\mathrm{Si} / \mathrm{SiGe}$ insulated with Alumina. Four couples were fabricated for a new thermal stability test for $300,400,500$ and $600^{\circ} \mathrm{C}$. A combination of Au and Ag epoxy was used to make contact for three couples and Molybdenum (Mo) metal was used for the fourth couple using laser assisted sputtering. Initial isothermal stability test on the Mo metal contact couple at $300^{\circ} \mathrm{C}$ for 100 hours shows less than $1 \%$ increase in resistivity of the contact resistance and stable power per formance. Testing is continuing. If this good performance continues, this represents a breakthrough in Hi-Z's search for an effective low resistivity joint and could pave the way for module fabrication. Figure 24 shows a mockup of a $2 \frac{1}{2}$ Watt QW module.

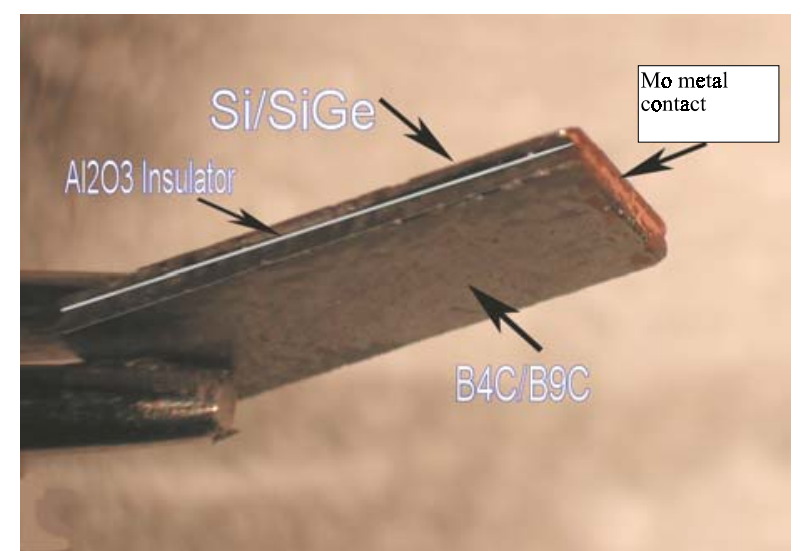

Figure 23. QW Si/SiGe-B $\mathrm{C}_{4} \mathrm{~B}_{9} \mathrm{C}$ Couple for Thermal Stability Test with MO Contact

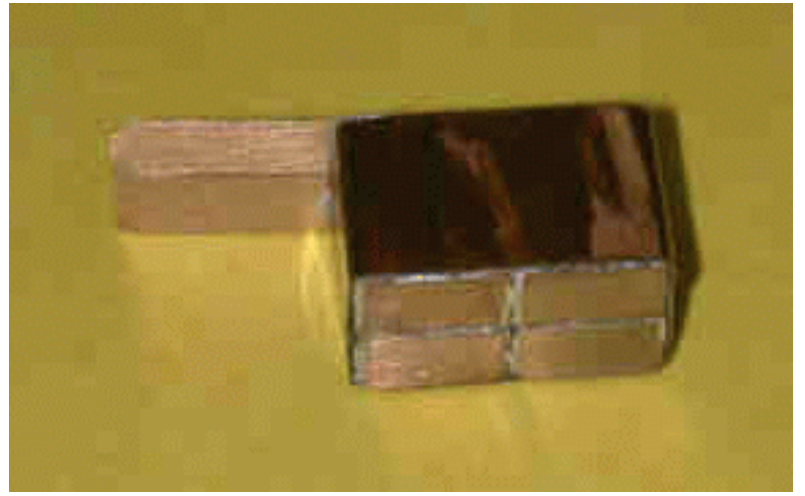

Figure 24. Mock up of $2 \frac{1}{2}$ Watt Quantum Well Module

\section{3-C. QUANTUM WELL DEVELOPMENT BY ELECTRON BEAM HOT WALL}

As an alternative to sputter-deposition of QW films, electron-beam heating to effect vaporization and deposition is being investigated. A primary advantage of this technique is the possibility of attaining very high deposition rates. A significant problem with electron-beam deposition is the possible decomposition of compounds during the deposition process, or at a minimum a serious change in stoichiometry of the deposited material. The hot-wall technique was developed to preclude such changes in stoichiometry by surrounding the evaporation space with a hot wall at higher temperature than the substrate on which the deposited film is formed. The hot-wall configuration has not previously been used with electron-beam heated sources. We have begun evaluation of this approach with the goal of preparing layered QW films.

Assembly of the system for development of techniques for film deposition using an electron-beam heated source coupled with a hot-wall deposition region has been completed and initial test depositions have begun. The system utilizes a four-hearth, water cooled source assembly mounted in an 18-inch diameter bell jar, pumped with an 8-inch diameter oil diffusion pump and a liquid- 
nitrogen cold trap. Vacuums in the $10^{-6}$ torr range are attained. The source is powered by a AircoTemescal $10 \mathrm{~kW}$ power supply $(10 \mathrm{kV}, 1 \mathrm{~A})$. An overall view of this system with the control consol is shown in Figure 25.

The source, hot wall, substrate and substrate shutter are shown in Figure 26. In order to show these components, the radiation-shield which normally surrounds the hot wall and substrate has been removed. The stainless steel hot-wall is heated by two band heaters and the copper substrate holder is heated with two cartridge heaters embedded in the holder.

Once the system was checked out, we continued the study of the dependance of film stoichiometry on deposition parameters. Analysis of the deposited films has been carried out using SEM/EDX at

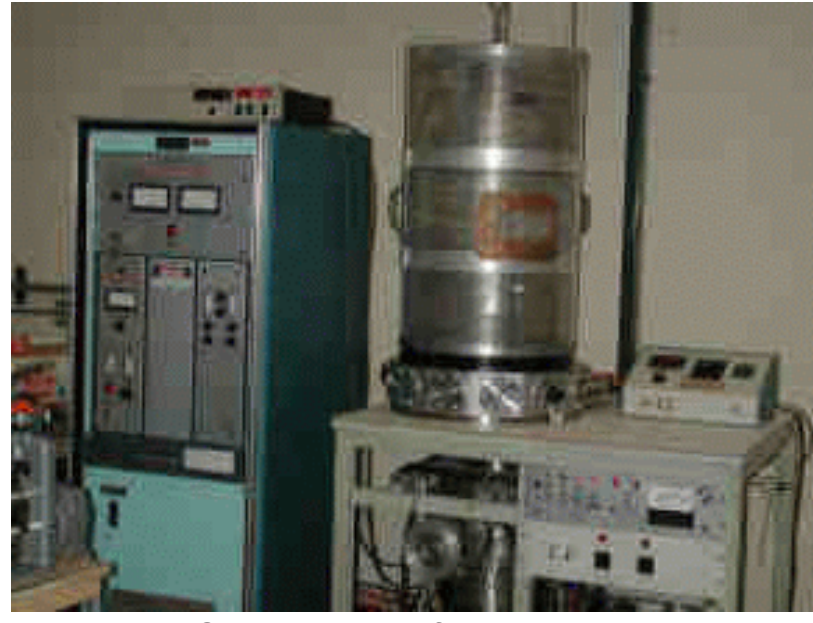

Figure 25. Overall View of Electron-BeamHeated Deposition System

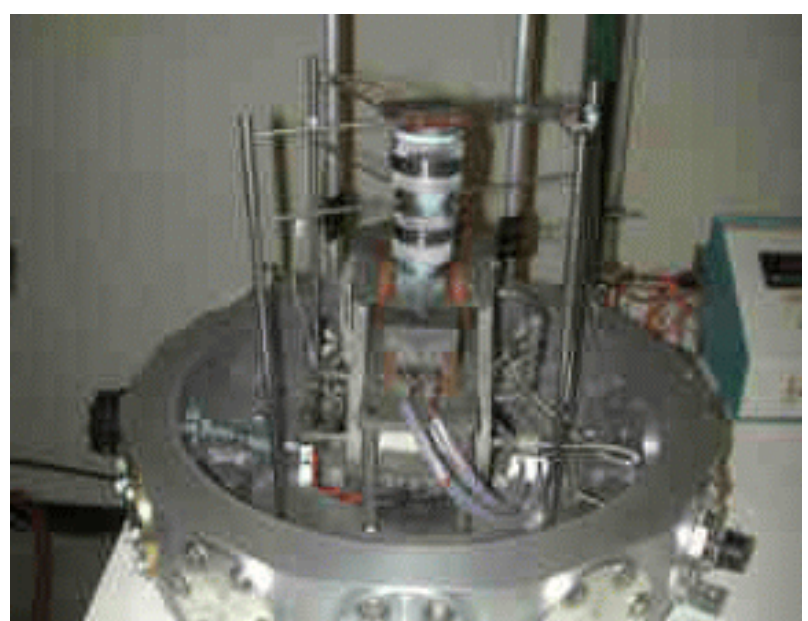

Figure 26. Source, Hot-Wall, Substrate Holder and Shutter

the General Atomics faculty in San Diego. We have used zirconia substrates to allow analysis of the stoichiometry of the deposited films without interference from the constituents of the substrate. In addition one film has been deposited on a polished, single-crystal Si substrate to determine the effect of the surface texture of the substrate on film morphology and growth characteristics. SEM examination of this film showed that it completely replicated the substrate smoothness with no evidence of any texture.

One of the two source materials used, prepared by powder-metallurgy techniques and obtained from Cercom, Inc., was difficult to use in our initial e-beam-depositions because of significant out-gassing during heating with the e-beam, almost certainly due to gasses trapped in the material during hotpressing, which caused significant pressure spikes shutting down the e-beam power supply. The material had to be heated very slowly to keep the vacuum-system pressure below acceptable limits. Acceptable sublimation rates of the $\mathrm{SiC}$ could be attained, but the heating cycle could take from 30 to 40 minutes, during which a significant amount of material was sublimed, limiting the amount available for deposition. We have subsequently developed a deposition protocol which allows use of the Cercom material. Source material is broken up with a steel mortar and pestle and screened to yield small pieces of approximately $1-\mathrm{mm}$ dimensions. Use of this material along with somewhat reduced beam power (typically $0.2 \mathrm{~A}$ at $6 \mathrm{kV}$ ) essentially eliminates the outgassing problem and still yields acceptable deposition rates. The samples prepared to date have used the Cercom material 
deposited with this protocol or POCO SuperSIC material which does not show the outgassing problem and can be used in bulk form as a source material.

Summary of Results. Table 2 summarizes the measured composition of most of the thin films of $\mathrm{SiC}$ prepared in this program. A number of early samples deposited from Cercom material which had significant $\mathrm{Cu}$ contamination inadvertently evaporated from the water cooled hearth are not listed here. Again the carbon-to-silicon ratio was calibrated by measurements made on bulk (Cercom) material which was assumed to have equal atomic concentrations of carbon and silicon.

Table 2. Summary of Measured Composition of Thin Films

\begin{tabular}{|c|c|c|c|c|c|c|}
\hline Sample & Supplier & $\mathbf{T}_{\mathbf{S}}\left({ }^{\circ} \mathbf{C}\right)$ & $\mathbf{T}_{\mathbf{w}}\left({ }^{\circ} \mathbf{C}\right)$ & $\mathbf{C}(\mathbf{a t} \%)$ & Si (at \%) & Al (at \%) \\
\hline $178-19$ & Cercom & 580 & 500 & 49.4 & 49.5 & 0.78 \\
\hline $178-27$ & Cercom & 500 & 590 & 57.7 & 41.0 & 1.25 \\
\hline $178-31$ & POCO & 500 & 580 & 70.2 & 29.8 & - \\
\hline $178-33$ & POCO & 500 & 620 & 71.0 & 15.0 & - \\
\hline $178-35$ & POCO & 500 & no wall & 42.2 & 57.8 & - \\
\hline $178-37$ & POCO & 500 & unheated & 57.1 & 42.9 & - \\
\hline $178-41$ & POCO & 600 & 650 & 55.5 & 44.5 & - \\
\hline $178-43$ & Cercom & 600 & 540 & 53.0 & 46.5 & 0.53 \\
\hline $178-45$ & POCO & 600 & 575 & 48.3 & 50.8 & - \\
\hline $178-59$ & Cercom & 600 & 540 & 50.1 & 49.3 & 0.67 \\
\hline $178-61$ & Cercom & 700 & 540 & 61.0 & 38.4 & 0.64 \\
\hline $178-63$ & Cercom & 750 & 535 & 64.9 & 34.5 & 0.54 \\
\hline $178-67$ & Cercom & 775 & 525 & 58.9 & 40.6 & 0.51 \\
\hline $178-69$ & Cercom & 760 & 560 & 45.2 & 54.0 & 0.76 \\
\hline
\end{tabular}

Samples numbered 178-33 and below were deposited using an 8 1/2 inch tall hot wall; those numbered 178-37 and above were deposited with a $31 / 2$ inch tall hot-wall.

The data on sample 178-19 and subsequently repeated on 178-45 and 178-58 (using both source materials) show that stoichiometric $\mathrm{SiC}$ is obtained with the wall temperature less than the substrate temperature, contrary to the usual expectation for hot-wall deposition. This is an important observation showing that appropriate hot wall and substrate temperature allow preparation of stoichiometric $\mathrm{SiC}$. 
It is also noted that depositions made with the substrate at an even hotter temperature, $700^{\circ} \mathrm{C}$ and above (178-61, -63 and -67), also yield samples which are very carbon-rich. In addition for these depositions a larger temperature difference between the substrate and the wall $\left(160\right.$ to $\left.225^{\circ} \mathrm{C}\right)$ exists. In the present installation wall temperatures above $\sim 600^{\circ} \mathrm{C}$ are not possible.

Finally, sample 178-69 appears to be an anomaly, being significantly Si-rich. This sample was twice the thickness of the others, but we do not see how this could be an explanation for the anomaly. Reanalysis of this sample verified that the high Si concentration in this sample was not due to an error in measurement.

Sample Conductivity. We have measured the resistivity of several of the deposited films and of the two source materials. Although we expected the POCO material, which is undoped, and the films deposited from it to be insulators, the Cercom $\mathrm{SiC}$, doped with $\sim 0.5$ at $\% \mathrm{Al}$ should be a p-type conductor, with the resistivity calculated below. The measurements of resistivity were made with an Alessi four-point probe apparatus which we use regularly in our laboratory and a Linear Research $L R-700$, a self-balancing bridge with excitation at $16 \mathrm{~Hz}$. The measured resistivity of the source material is greater than $700 \mathrm{kS}-\mathrm{cm}$. Appropriate doping of the material will reduce the resistivity to desired values.

As seen in Table 2 in films deposited from Cercom source material the concentration of $\mathrm{Al}$ is between approximately 0.5 and $0.75 \mathrm{at} \%$. Analysis of the source material showed an $\mathrm{Al}$ concentration of $0.48 \mathrm{at} \%$. In $\mathrm{SiC}$ this concentration corresponds to a density of $\mathrm{Al}$ atoms in the $\mathrm{SiC}$ of $2.4 \times 10^{20} \mathrm{~cm}^{-3}$. From published data for $\mathrm{SiC}$, the acceptor level of $\mathrm{Al}$ is at $0.2 \mathrm{eV}$ and the hole mobility is $100 \mathrm{~cm}^{2} / \mathrm{V}$-s. From these numbers we calculate the expected resistivity of this material to be $0.1 \mathrm{~S}-\mathrm{cm}$. The mobility value used in this calculation is for an acceptor density of $10^{16} \mathrm{~cm}^{-3}$, four orders of magnitude below our calculated value, so a mobility in our material lower than 100 $\mathrm{cm}^{2} / \mathrm{V}$-s is likely, but it is hard to believe that the inability can be low enough to explain the very high measured resistivities. Clearly additional work is needed to explain the source of these unexpected low values of resistivity. Possibly a different conduction mechanism exists in SiC at those high doping levels.

\section{Future Plans.}

1. Understanding of the resistivity of the Cercom source material and the films deposited from it. We will carry out an alternate analysis (as yet unchosen) of the aluminum concentration, at least in the starting material and if possible in select films and will make alternate measurements of the resistivity of the starting material, using deposited metal electrodes, as opposed to the pressure contacts used in the Alessi probe. An additional literature search will also be made to better understand the conduction mechanism in doped $\mathrm{SiC}$.

2. Si-Ge deposition. While the hot wall is set up for e-beam deposition it has been decided to deposit a few films of this material in the hot-wall configuration to determine at least in a preliminary way the utility of this deposition process for preparation of $\mathrm{Si}-\mathrm{Ge}$. The first few depositions of SiGe onto a Kapton substrate have yielded smooth, crack-free films with excellent adherence to the films. An extended number of depositions will not 
be needed to determine the wall and substrate temperatures needed to obtain films with the desired Si to Ge ratio.

\section{3-D CLARKSON/NYSERDA AETEG PROJECT}

Phase II of the program has been completed, Figures 27 through 34 shows documentation of various stages of Hi-Z's fabrication of the AETEG subassemblies and the final bench test. The Power Control System utilizes Hi-Z's Power Conditioning Unit (PCU), designed and built at Hi-Z (shown in Figures 35 and 36). The PCU transforms the voltage supplied by the AETEG to the voltage of the DC bus. It contains an electronic match load device and a DC-DC converter circuit to perform this function, and is patterned after Hi-Z's design of an existing thermoelectric battery charger, model HZ-24. The AETEG was mounted on the test truck, shown in Figure 37. The AETEG experienced electrical control problems in the Delphi tests aboard the test truck. At some point, when engine load was growing and exhaust temperature reached a maximum, the TEG voltage rapidly went down to 4-5V and then recovered. The most likely reason for the drop in output voltage was a short circuit somewhere in the system. The main reason for this conclusion is that the voltage did not drop completely to minimum, the failure, which would have been the case if an open circuit had occurred. The short could have happened within th AETEG, in the wiring from the AETEG to the CPU, and been within the CPU. The last possibility is less likely since the CPU was carefully tested before and afer the incident, and any semiconductor failure merely would have resulted in limiting the CPU's input voltage to the battery's potential. The unit was removed and shipped to Hi-Z for trouble shooting. A failure of PCU circuit TLC 555 component in the electrical control unit was discovered and the problem was fixed. Hi-Z then ran performance tests on the unit which showed efficiency of $88 \%$ average performance of the PCU which is normal. Six pages of performance data and graphs were compiled and retained as proof of "Before and After" performance. These were contained in the Fourteenth Quarterly Report. The AETEG generated about $255 \mathrm{~W}$ when city water was used as a coolant, and about $150 \mathrm{~W}$ when engine coolant was used. The next phase has been started. This would include a commercialization effort, performed by Clarkson, with input by Hi-Z.

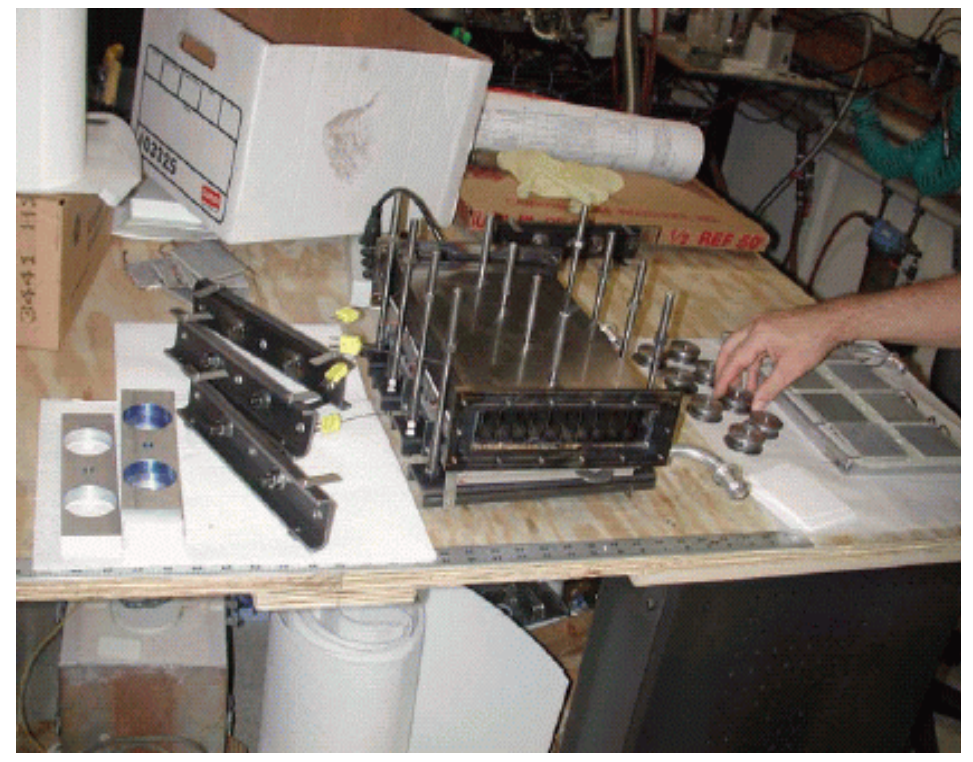

Figure 27. AETEG Generator Sub-assemblies and Parts 


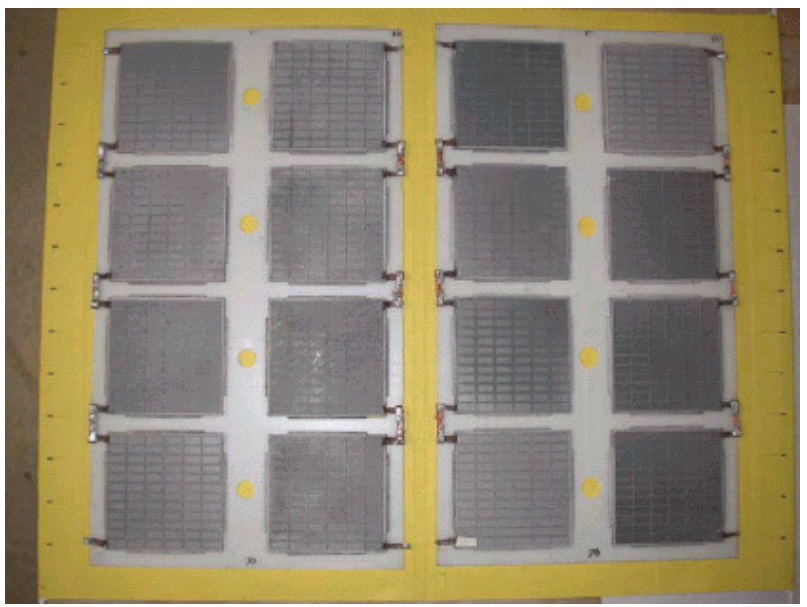

Figure 28. Wired HZ-20 Module Arrays

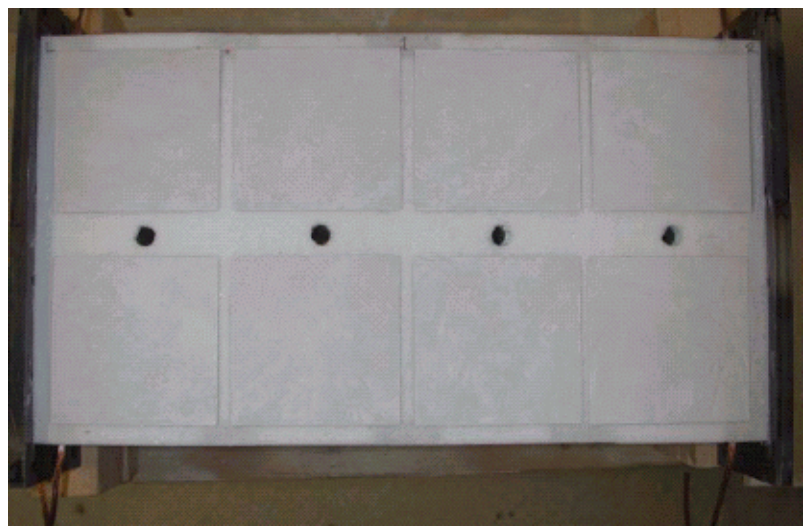

Figure 30. Additional Insulation Installed

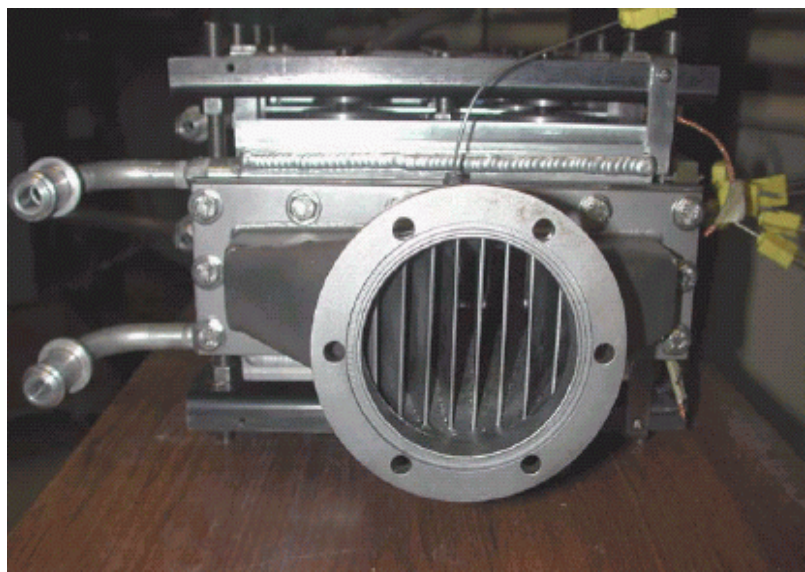

Figure 32. View of Inlet Diffuser Vanes

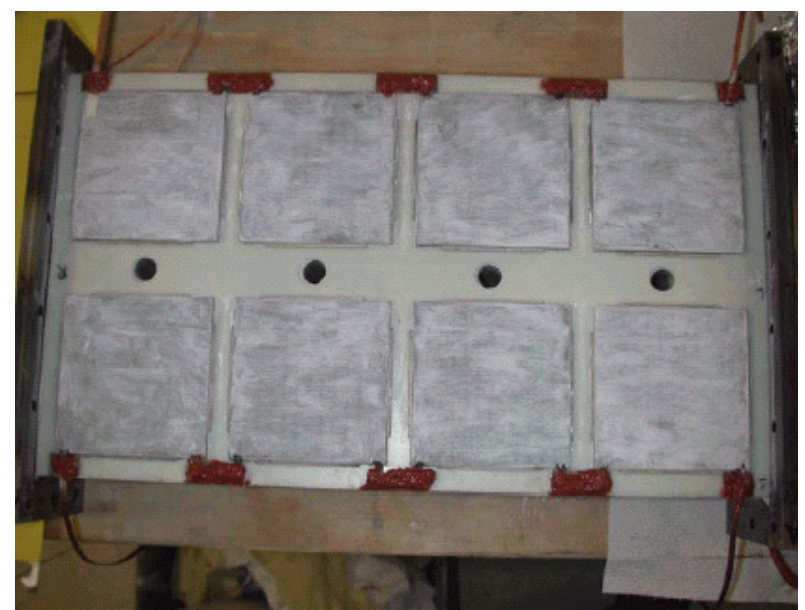

Figure 29. Additional Insulation Installed

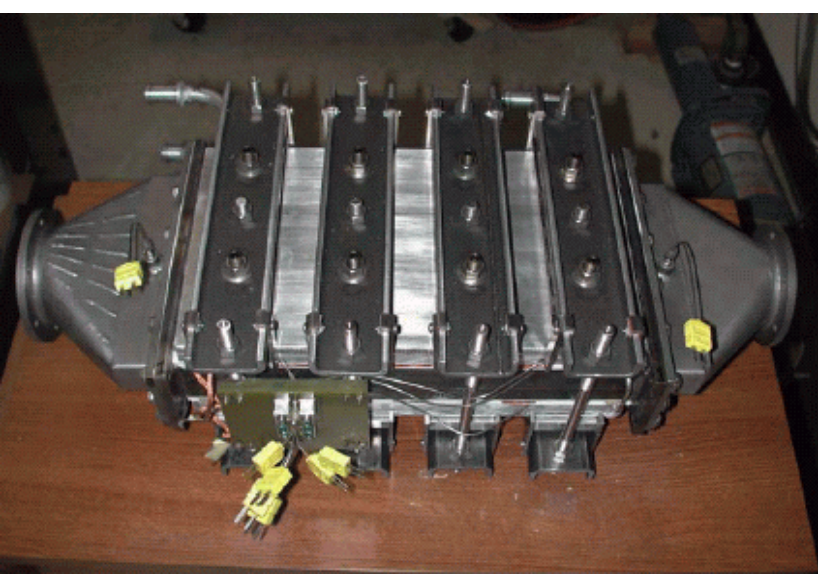

Figure 31. Assembled AETEG Without Case

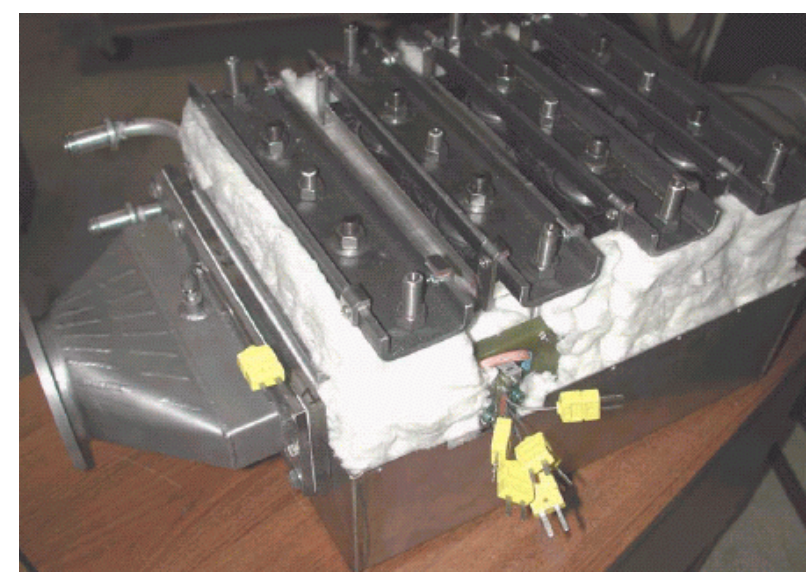

Figure 33. Insulation Being Installed 


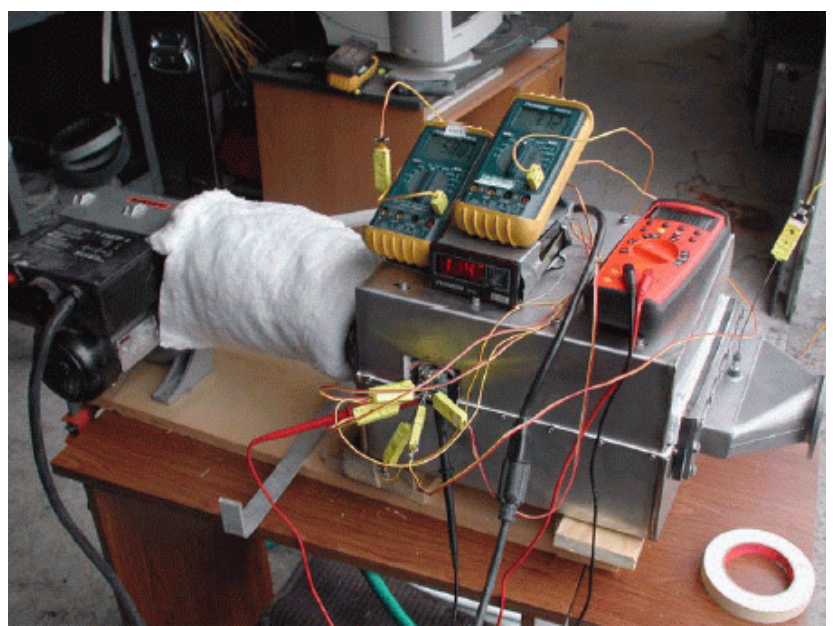

Figure 34. AETEG Connected to Air Heater

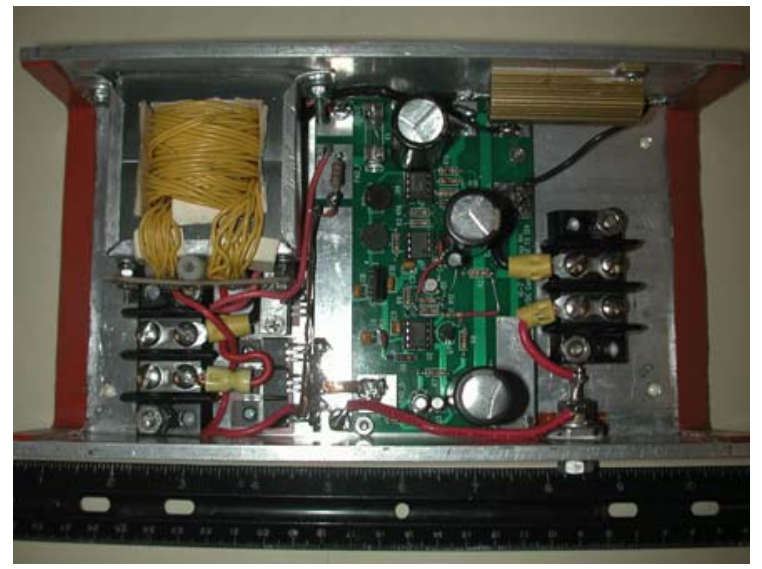

Figure 36. PCU Final Configuration

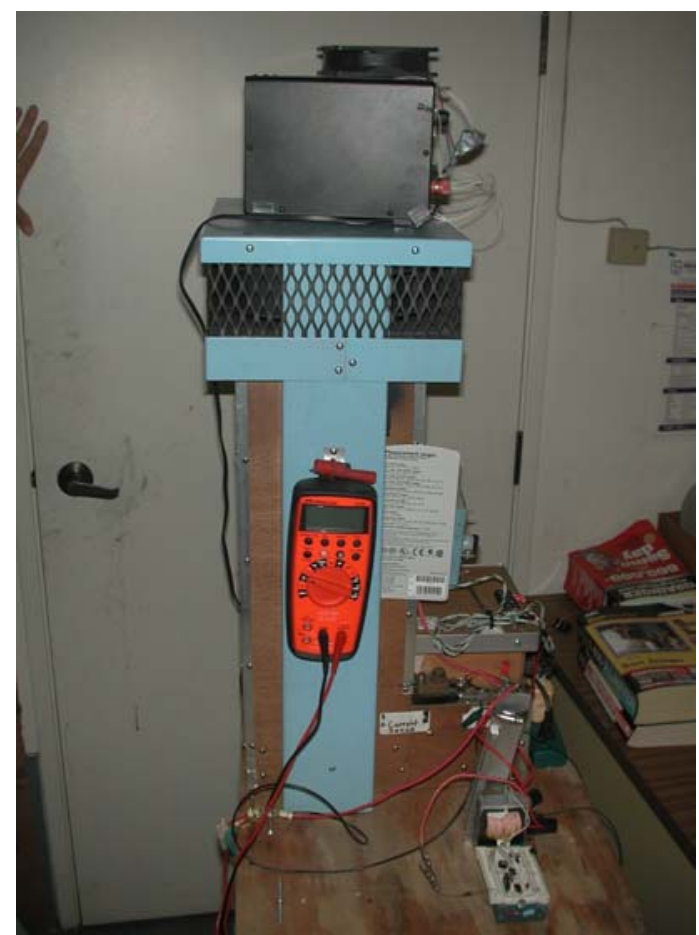

Figure 35. Power Conditioning Unit (PCU) Bench Test

\section{3-E. OHIO STATE LTETG PROJECT}

The program consisted of refurbishing an existing TEG, outfitting it with eighteen 14 Watt modules, and

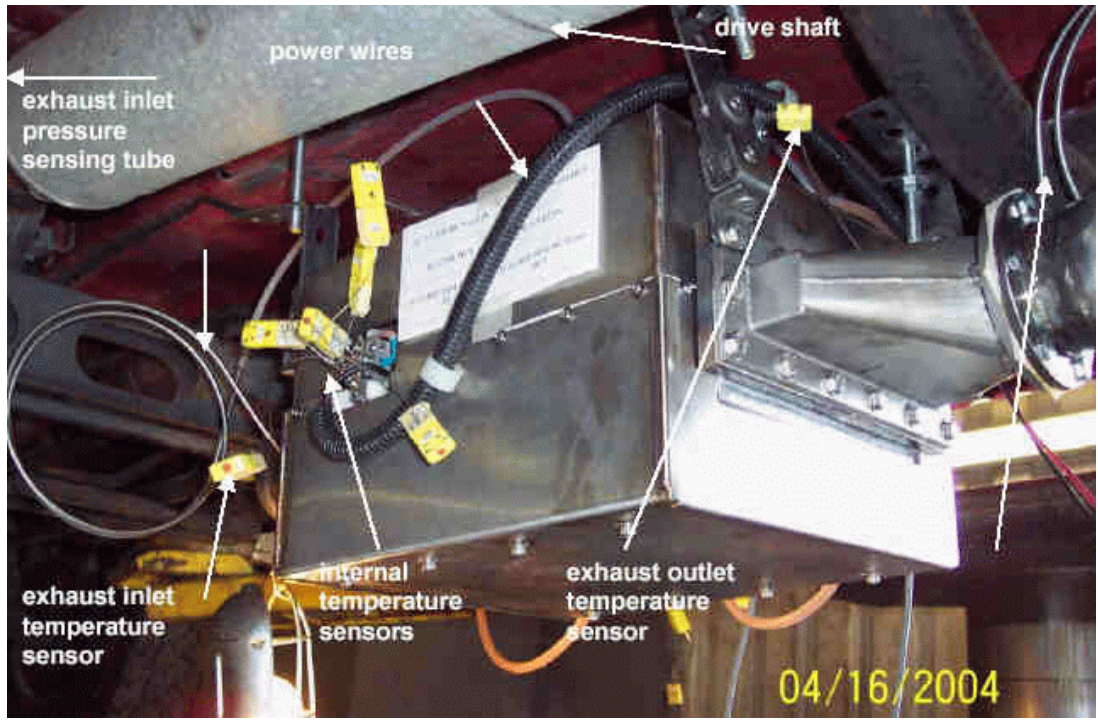

Figure 37. Photograph of a $\mathbf{3 0 0}$ Watt Generator Mounted Beneath Truck 
subjecting it to the hot air blower testing to confirm performance. The unit was then shipped to Ohio State and awaits further action. Figures 38, 39, 40, 41, 42 and 43 show the LTEG during various stages of assembly and testing.

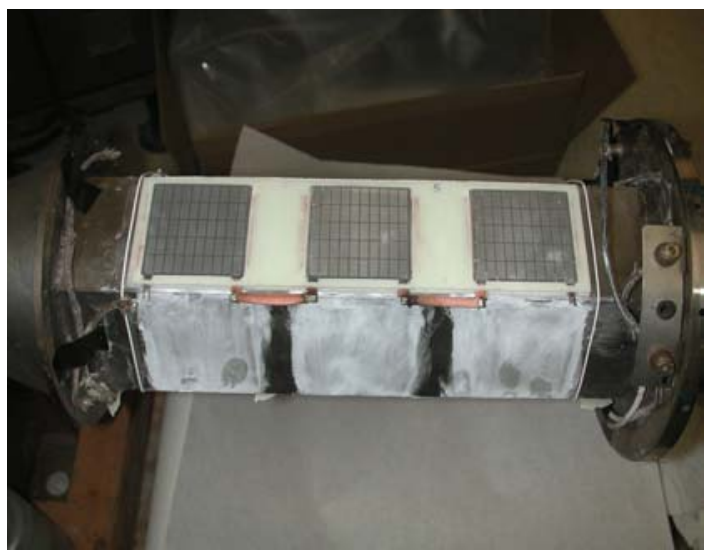

Figure 38. $200 \mathrm{~W}$ TEG for Hybrid Electric Vehicle Underassembly

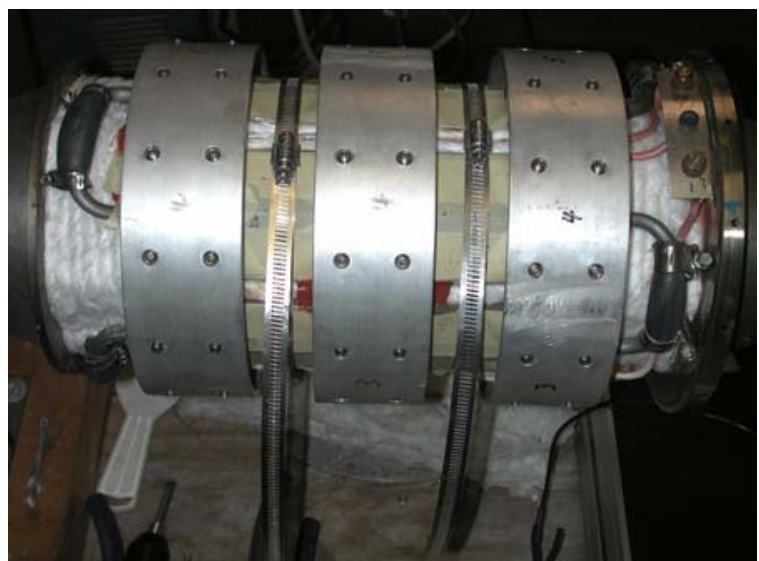

Figure 40. 200 W TEG Completely Assembled

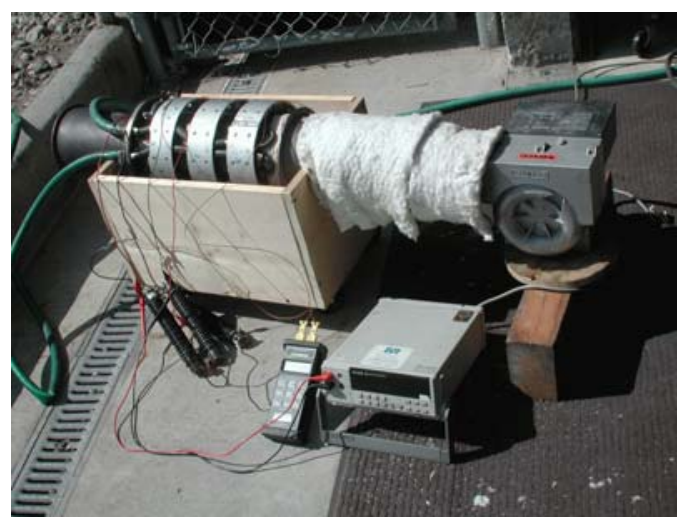

Figure 42. 200 W TEG Hot Air Blower Test

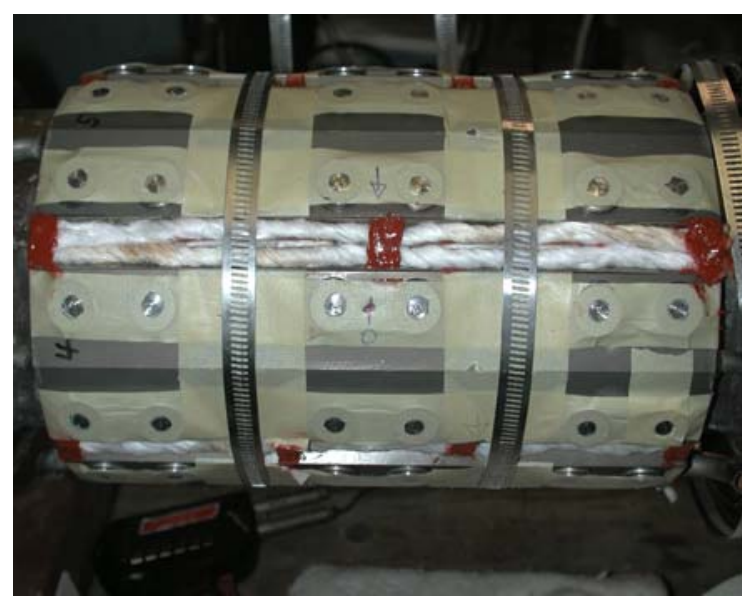

Figure 39. $200 \mathrm{~W}$ TEG. All modules are in place

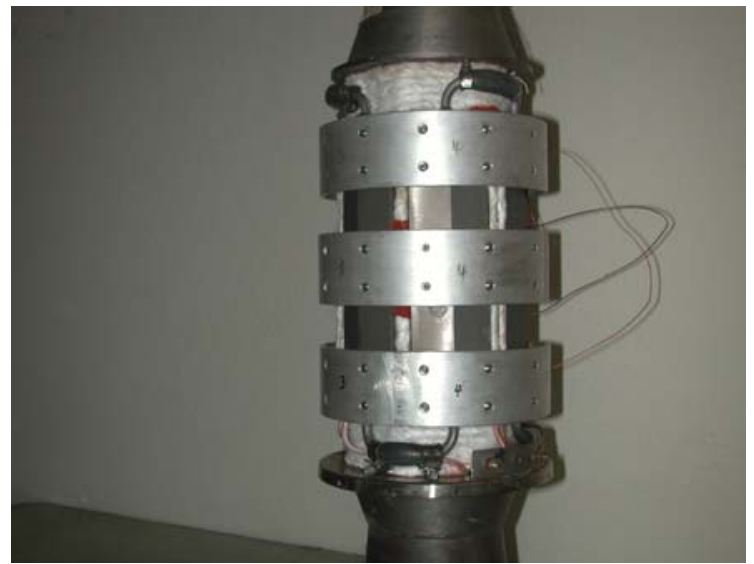

Figure 41. 200 W TEG Ready for Test

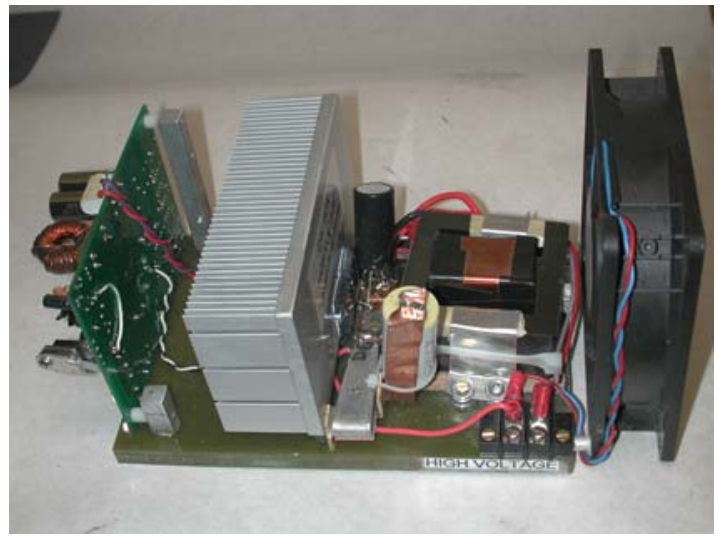

Figure 43. $200 \mathrm{~W}$ TEG Power Management System 


\section{3-F. TACOM UNDERARMOR 10 kW GENERATOR}

QW Thermoelectric Unit. The module and eggcrate are designed for the exhaust temperature distribution, exhaust flow rate, space envelope and power density operation for the Stryker vehicle. A thermoelectric unit comprising the eggcrate and the heat exchangers is being designed/fabricated. The design includes heat transfer enhancements on both the hot and cold heat exchangers. A schematic is shown in Figure 44.

This quantum well thermoelectric unit has the following features:

- A robust structure that maintains compressive force over all temperatures for the QW thermoelectric module, the alumina insulators, thermal grease, and high performance liquid coolant heat exchanger to ensure continuous thermal contact and high heat transfer.

- A high performance thermoelectric module that has 100 elements, and provides greater than $70 \mathrm{~W}$ at $12 \mathrm{~V}$ at a temperature difference of $200 \mathrm{~K}$.

- A modest pressure drop (3 psi), low thermal resistance $(0.05 \mathrm{~K} / \mathrm{W})$, individual module heat exchanger that is soldered in series or parallel to other coolant heat exchangers.

- A smooth flat or circular sectioned surface to mate with the hot side exhaust pipe.

- A method to test QW performance before installation in exhaust system.

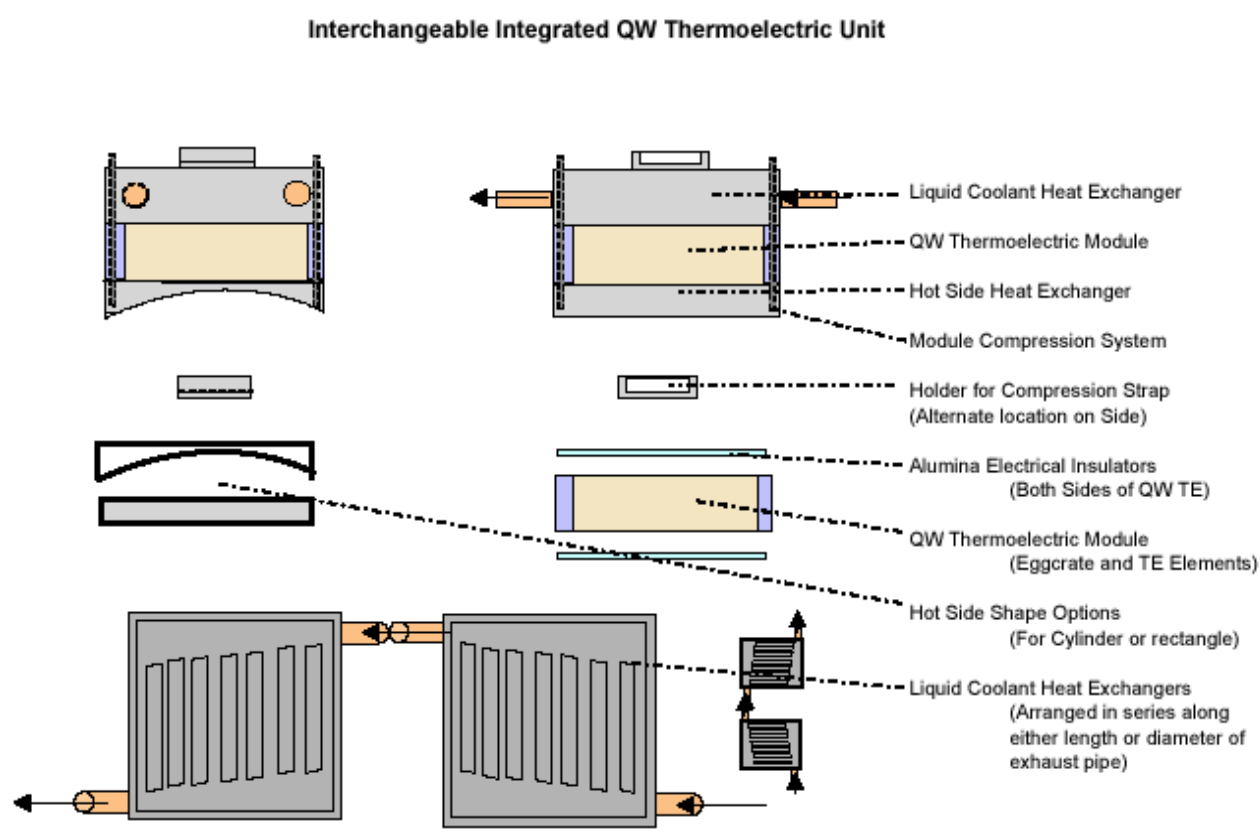

Figure 44. Interchangeable Integrated QW Thermoelectric Unit 
QW Thermoelectric Generator. A schematic of the quantum well thermoelectric generator is shown on Figure 45.

Key features of the QW generator are:

- Individual QW thermoelectric are designed for temperatures at each axial location.

- Individual QW thermoelectric units with modules are preloaded and tested before attachment to the steel heat exchanger.

- The steel heat exchanger is internally finned to augment heat transfer and matches the pressure drop of the muffler and the exhaust diameter.

- The QW TE modules are fastened to the steel heat exchanger by constant torque type 304 stainless steel worm drive clamps to maintain compressive force on each of the eight modules around the octagon. Each clamp has only one Belleville clamp, whereas the prior $1 \mathrm{~kW}$ TE generator had one clamp on each of the thermoelectric modules. Thus, now only eight Belleville clamps are needed, compared to 72 in a prior design. Each QW TE module is individually in compression so repeatable assembly is now possible.

Cooling Arrangement

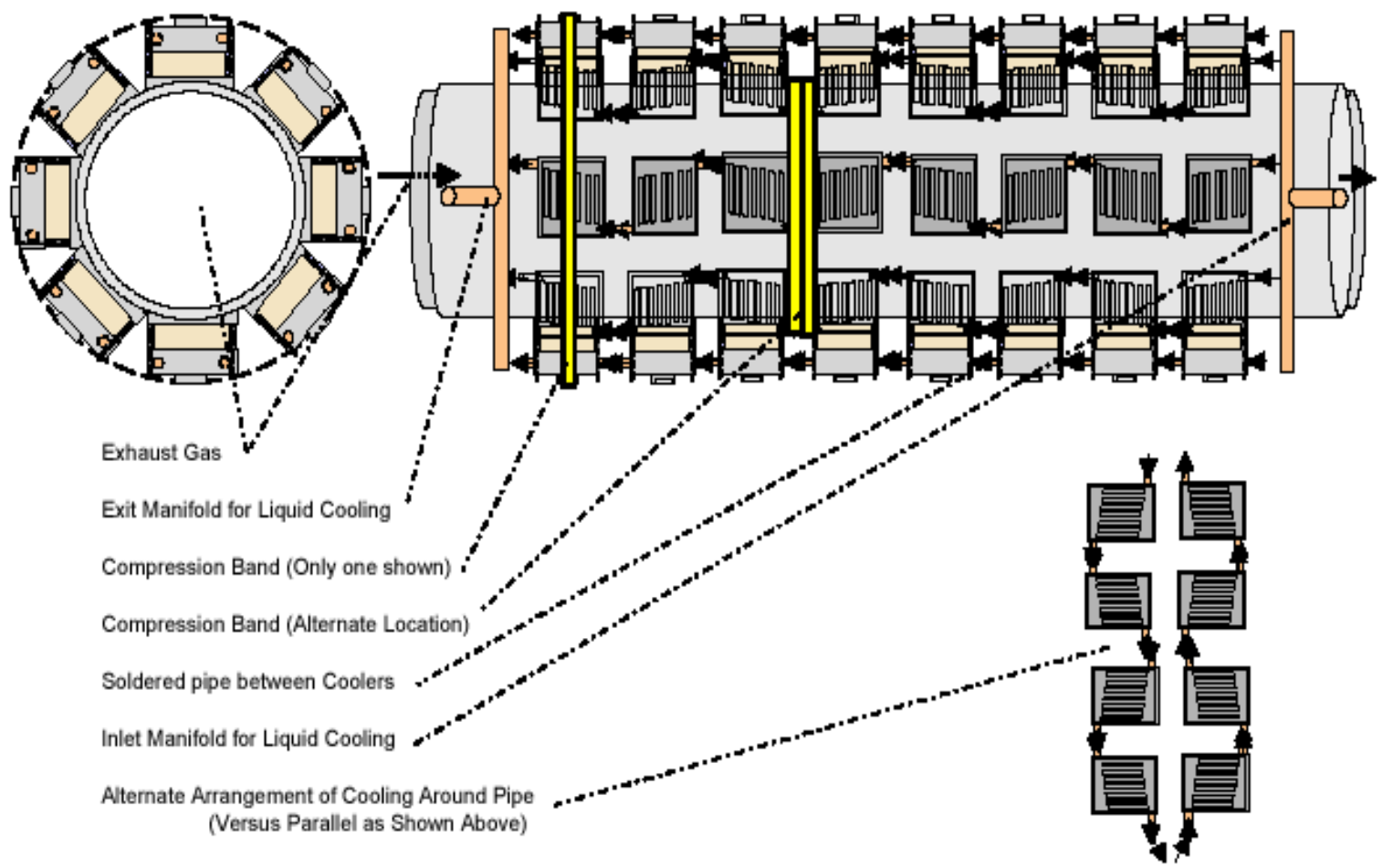

Figure 45. Interchangeable Integrated QW Thermoelectric Generator 
- Each of the individual QW TE unit liquid heat exchangers is soldered when in place on the generator.

- Heat exchanger arrangement leads to easy modification to either series or parallel fluid flow to match pressure drop of Stryker vehicle, or another vehicle application.

- Also, module electrical arrangement leads to easy modification to either series or parallel current to provide voltage for Stryker vehicle, or another vehicle application.

Thermoelectric Couple/Literature Data and QW TE Module. Hi-Z is designing a new QW TE module for the Stryker application. Important considerations are the thermal conductivity of the substrate, which is a heat loss, and the thermal conductivity of the QW thermoelectric material that determines figure-of-merit.

Hi-Z has obtained data on the composite and the substrate thermal conductivity for an 11 micron Ptype $\mathrm{B}_{4} \mathrm{C} / \mathrm{B}_{9} \mathrm{C}$ QW film on a 5 micron Si substrate. The composite's measured thermal conductivity $0.5 \mathrm{~W} / \mathrm{cm} \mathrm{K}$, and the Si substrate's measured thermal conductivity by itself is $0.12 \mathrm{~W} / \mathrm{cm} \mathrm{K}$. To determine the thermal conductivity of the $\mathrm{B}_{4} \mathrm{C} / \mathrm{B}_{9} \mathrm{C}$, the following calculations give the QW film thermal conductivity for parallel or series thermal resistance. This gives a $\mathrm{QW}$ film thermal conductivity of $0.67 \mathrm{~W} / \mathrm{cm} \mathrm{K}$.

However, this is different than published data. The data presented by Marvin Moss (Sandia) in "Thermal Conductivity of Boron Carbides" in Novel Refractory Semiconductors, Vol 97, 1987 MRS is $0.17 \mathrm{~W} / \mathrm{cm} \mathrm{K}$ for $\mathrm{B}_{4} \mathrm{C}$ and $0.06 \mathrm{~W} / \mathrm{cm} \mathrm{K}$ for $\mathrm{B}_{9} \mathrm{C}$. For a parallel $\mathrm{B}_{4} \mathrm{C} / \mathrm{B}_{9} \mathrm{C}$ circuit, the effective thermal conductivity $\mathrm{B}_{4} \mathrm{C} / \mathrm{B}_{9} \mathrm{C}$ is $0.115 \mathrm{~W} / \mathrm{cm} \mathrm{K}$.

With pure single crystal silicon as the composite may have performed prior to other constituent diffusion, the thermal conductivity is $1.45 \mathrm{~W} / \mathrm{cm} \mathrm{K}$ from numerous literature sources. Using this value, the thermal conductivity of $\mathrm{B}_{4} \mathrm{C} / \mathrm{B}_{9} \mathrm{C}$ is $0.065 \mathrm{~W} / \mathrm{cm} \mathrm{K}$ when using a composite $\mathrm{K}$ of $0.5 \mathrm{~W} / \mathrm{cm}$ $\mathrm{K}$. If the silicon conductivity is $1.25 \mathrm{~W} / \mathrm{cm} \mathrm{K}$ as shown on Figure 46 , then the $\mathrm{B}_{4} \mathrm{C} / \mathrm{B}_{9} \mathrm{C}$ thermal conductivity is $0.12 \mathrm{~W} / \mathrm{cm} \mathrm{K}$. These are closer to $\mathrm{B}_{4} \mathrm{C} / \mathrm{B}_{9} \mathrm{C}$ published data, indicating single crystal silicon performance in the composite measurement.

In summary, we will base the thermal conductivity of $\mathrm{B}_{4} \mathrm{C} / \mathrm{B}_{9} \mathrm{C}$ at $0.115 \mathrm{~W} / \mathrm{cm} \mathrm{K}$ consistent with literature, and the silicon substrate at $0.12 \mathrm{~W} / \mathrm{cm} \mathrm{K}$ consistent with doped silicon.

QW TE Module. Today's HZ-14 $\mathrm{Bi}_{2} \mathrm{Te}_{3}$ based module is 2.35 in $\mathrm{x} 2.35$ in and 0.200 thick where each of the $100 \mathrm{TE}$ element material regions is 0.200 in square $\mathrm{x} 0.155$ in deep.

A number of module options have been considered as shown in Table 3. 


\section{Thermal Conductivity of $\mathrm{P}$ leg $\mathrm{B}_{4} \mathrm{C} / \mathrm{B}_{9} \mathrm{C} \mathrm{QW}$ for}

\section{Composite \& Si Substrate Thermal Conductivity}

Composite Parallel or Series with QW film 11 \& Si substrte 5 microns

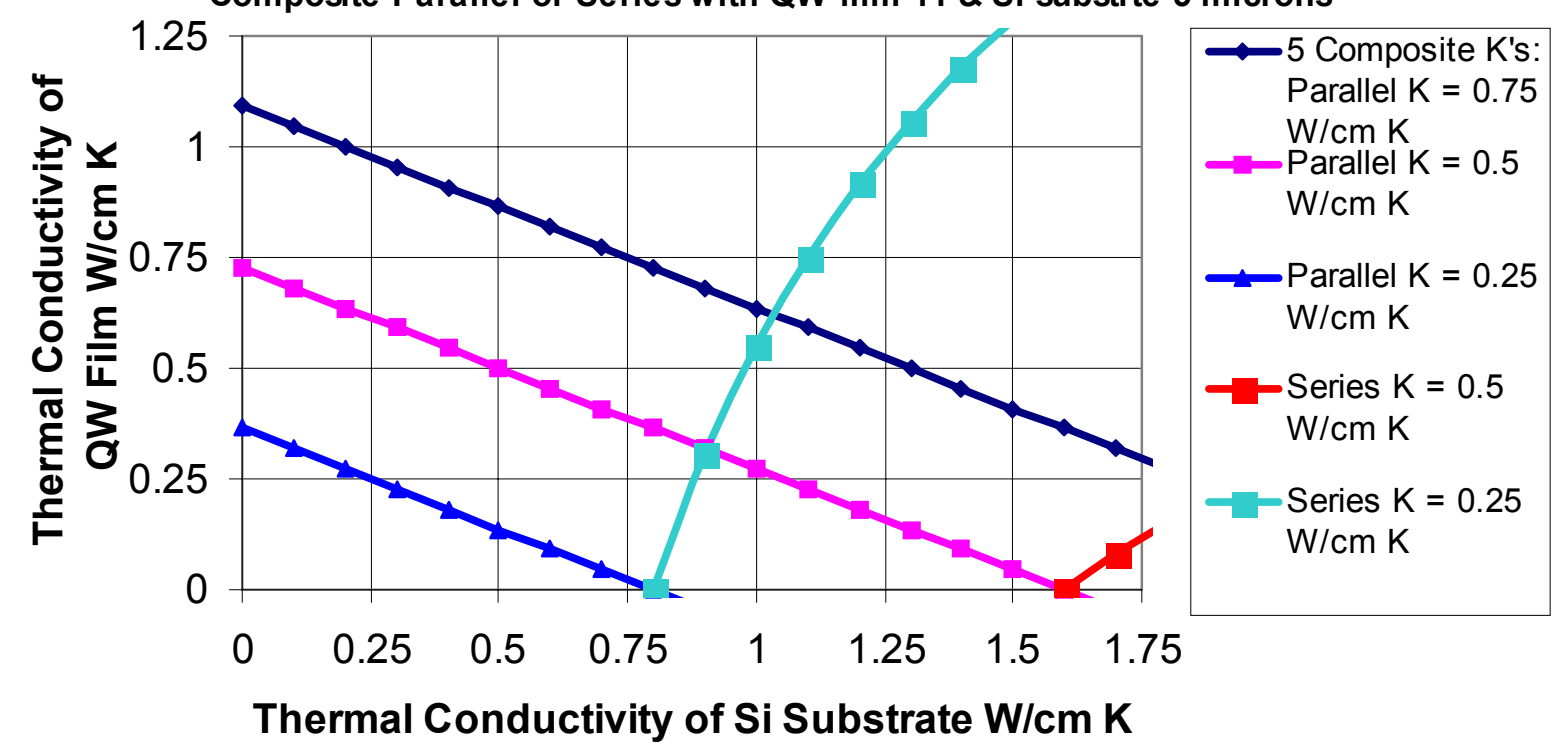

Figure 46. Thermal Conductivity of $\mathrm{P}$ Leg $\mathrm{B}_{4} \mathrm{C} / \mathrm{B}_{9} \mathrm{C}$ QW Composite and Si Substrate Thermal Conductivity

Table 3. Module Options

\begin{tabular}{|l|l|c|l|l|}
\hline \multicolumn{1}{|c|}{$\begin{array}{c}\text { Module } \\
\text { Comparison }\end{array}$} & $\begin{array}{c}\text { Outside } \\
\text { Dimension - in. }\end{array}$ & $\begin{array}{c}\text { Number of } \\
\text { Elements }\end{array}$ & \multicolumn{1}{c|}{$\begin{array}{c}\text { Element Size } \\
\text { in. }\end{array}$} & \multicolumn{1}{c|}{$\begin{array}{c}\text { Element Size } \\
\text { cm }\end{array}$} \\
\hline $\mathrm{HZ}-14$ & $\begin{array}{l}2.403 \times 2.403 \times \\
0.200\end{array}$ & 100 & $0.200 \times 0.200 .0 .155$ & $0.508 \times 0.508 \times 0.394$ \\
\hline $\begin{array}{l}\text { QW with equal } \\
\mathrm{N} \& \mathrm{P} \text { legs }\end{array}$ & $\begin{array}{l}2.403 \times 2.403 \times \\
0.518\end{array}$ & 100 & $0.141 \times 0.141 \times 0.400$ & $0.358 \times 0.358 \times 1.02$ \\
\hline $\begin{array}{l}\text { QW with } \\
(\mathrm{L} / \mathrm{A}) \mathrm{P} /(\mathrm{L} / \mathrm{A}) \mathrm{N}=2 \\
\text { via length }\end{array}$ & $\begin{array}{l}2.403 \times 2.403 \times \\
0.518\end{array}$ & 100 & $\begin{array}{l}0.141 \times 0.141 \times 0.200 \\
\mathrm{~N} \text { leg \& } 0.400 \mathrm{P} \text { leg }\end{array}$ & $\begin{array}{l}0.358 \times 0.358 \times 0.508 \\
\mathrm{~N} \mathrm{leg} \mathrm{\&} 1.02 \mathrm{P} \text { leg }\end{array}$ \\
\hline $\begin{array}{l}\text { QW with } \\
(\mathrm{L} / \mathrm{A}) \mathrm{P}(\mathrm{LA}) \mathrm{N}=2\end{array}$ & $\begin{array}{l}2.403 \times 2.403 \times \\
0.518\end{array}$ & 144 & $\begin{array}{l}0.141 \times 0.141 \mathrm{~N} \text { leg \& } \\
0.100 \times 0100 \mathrm{P} \text { leg } \times\end{array}$ & $\begin{array}{l}0.358 \times 0.358 \mathrm{~N} \text { leg \& } \\
0.254 \times 0.254 \mathrm{P} \text { leg } \times \\
1.02\end{array}$ \\
\hline $\begin{array}{l}\text { QW with HZ-14 } \\
\text { elements and } \\
\text { thicker module }\end{array}$ & $\begin{array}{l}1.403 \times 2.403 \times \\
0.200\end{array}$ & 100 & $0.200 \times 0.200 \times 0.591$ & $0.508 \times 0.508 \times 1.50$ \\
\hline
\end{tabular}


Thicker QW modules compared to HZ-14 are currently under investigation to better match the QW thermal conductance with that of the hot gas exhaust stream.

QW TE Module Efficiency. The predicted performance for the current and modified HZ-14 module, is compared to the maximum achievable from Carnot considerations.

The calculated performance is shown for a cold side thermoelectric temperature of $125^{\circ} \mathrm{C}$ that is characteristic of the Stryker coolant. The hot side temperature is the temperature at the thermoelectric module. A generator design to achieve this is treated separately and must include heat transfer from the hot exhaust gas and the cold liquid coolant, including heat flux through the module. These advanced quantum well materials have the capability to deliver a large heat flux; however, we consider the ability of the exhaust stream to deliver the heat flux as shown in a later section on the overall generator performance.

Several important conclusions are drawn from the efficiency chart (Figure 47). As a reference, the best possible heat engine performance is shown as the Carnot efficiency. For the specific measured quantum well material properties of $\mathrm{N}$-type $\mathrm{Si} / \mathrm{SiGe}$ and $\mathrm{P}$-type $\mathrm{B}_{4} \mathrm{C} / \mathrm{B} 9 \mathrm{C}$, the maximum percent of Carnot is somewhat over $35 \%$. With 11 microns of the quantum well material on a 5 micron substrate, the percent of Carnot is a bit over $30 \%$. The absolute efficiencies are also shown. For instance, the $\mathrm{N}$-type $\mathrm{Si} / \mathrm{SiGe}$ and $\mathrm{P}$-type $\mathrm{B}_{4} \mathrm{C} / \mathrm{B} 9 \mathrm{C}$ give an efficiency of $15.5 \%$ at hot side temperature of $400 / \mathrm{C}$. For a higher substrate thermal conductivity of $1.4 \mathrm{~W} / \mathrm{cmK}$, the efficiency is reduced to $4.1 \%$ at hot side temperature of $400 \%$ C. For a doped Si substrate thermal $\mathrm{k}$ of $0.12 \mathrm{~W} / \mathrm{cmK}$, the efficiency is $10.5 \%$. A SiGe substrate will approach $15 \%$ efficiency.

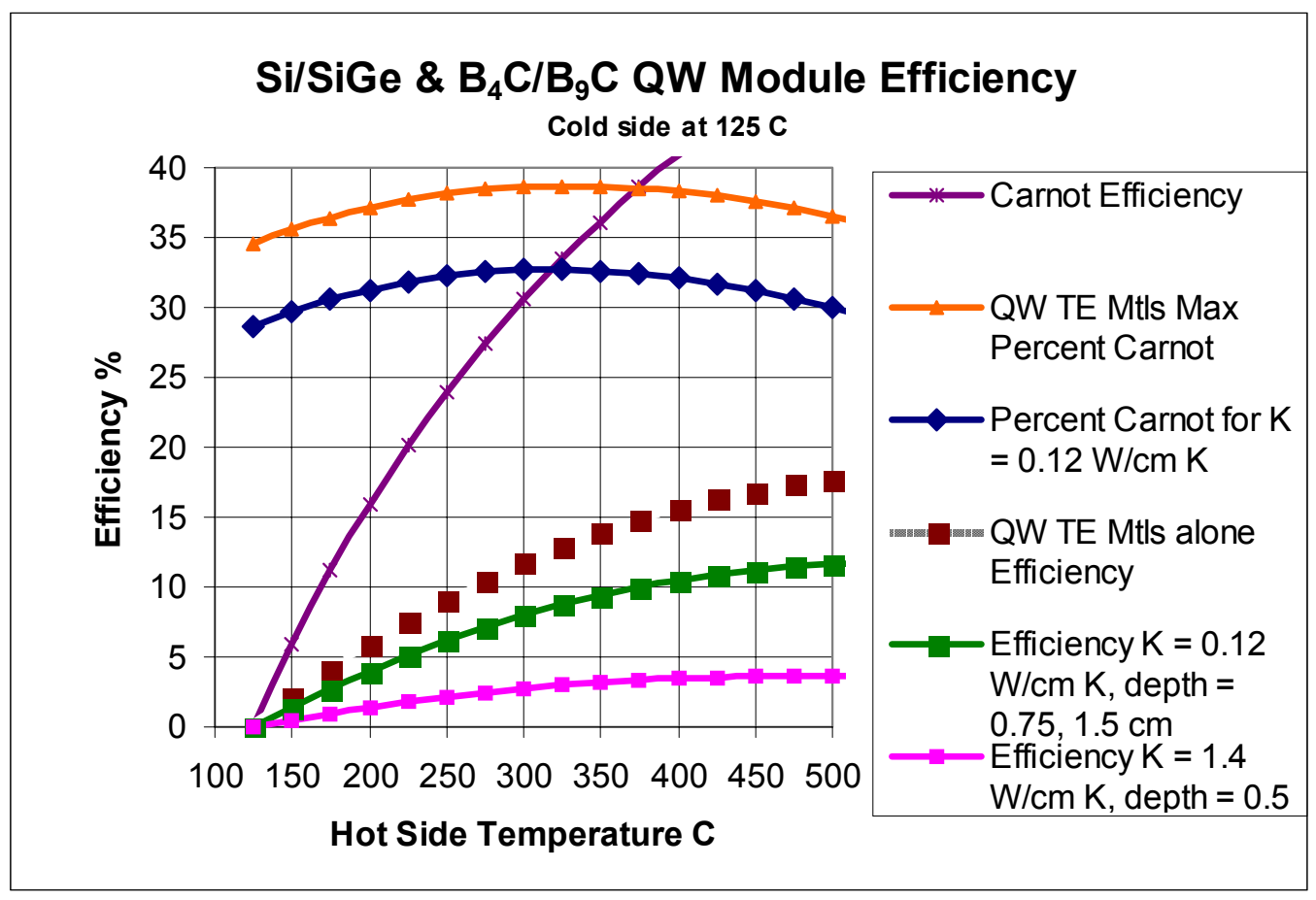

Figure 47. Si/SiGe and $\mathrm{B}_{4} \mathrm{C} / \mathrm{B}_{9} \mathrm{C}$ QW Module Efficiency 
An important decision is how to match the heat flux through the module, with the ability of the exhaust stream to deliver this heat flux. Cold side heat transfer coefficients are from 4.0 to $40 \mathrm{~W} / \mathrm{K}$, hot side from fluid is $0.5 \mathrm{~W} / \mathrm{K}$ to $2.0 \mathrm{~W} / \mathrm{K}$ for gas to $25 \mathrm{~W} / \mathrm{K}$ for liquid.

The module heat flux shown on Figure 48 as a function of hot side temperature where the cold side is at $125^{\circ} \mathrm{C}$. The current HZ-14 module is shown as the lower curve up to $350^{\circ} \mathrm{C}$. This is higher than the temperature of $250^{\circ} \mathrm{C}$ recommended for long term operation. At a temperature difference of $200^{\circ} \mathrm{C}$ (hot side at $325^{\circ} \mathrm{C}$ ), the heat flux is $10.3 \mathrm{~W} / \mathrm{cm}^{2}$. For N-type SiGe and P-type $\mathrm{B}_{4} \mathrm{C} / \mathrm{B}_{9} \mathrm{C}$ quantum well materials in the same size HZ-14 eggcrate, the heat flux is $94.3 \mathrm{~W} / \mathrm{cm}^{2}$. This higher heat flux is due to QW materials with higher Seebeck coefficient (V/C) and higher thermal conductivity $(\mathrm{W} / \mathrm{cmK})$ than current $\mathrm{Bi}_{2} \mathrm{Te}_{3}$ materials. The net effect is the ability to accommodate a very large heat flux.

The high heat flux of QW TE module, i.e., the high effective thermal conductance of the QW TE module, in the same size as the $\mathrm{Bi}_{2} \mathrm{Te}_{3}$ module, includes the $\mathrm{L} / \mathrm{A}$ of quantum well materials, quantum well material properties, quantum well substrate and eggcrate. For instance, the effective conductance of the present $\mathrm{Bi}_{2} \mathrm{Te}_{3}$ TE module is $1.4 \mathrm{~W} / \mathrm{C}$ whereas a $\mathrm{QW}$ TE module in the same space is $\sim 10 \mathrm{~W} / \mathrm{C}$. The application implication is that the temperature difference would be taken across the gas and liquid and not the thermoelectric generator.

The middle two curves show how the modified quantum well eggcrate geometry lowers the heat flux through the module. Higher heat flux translates into higher electrical power. However, a QW TE generator gives an effective conductance of $1.0 \mathrm{~W} / \mathrm{C}$ at $4.0 \mathrm{~cm}$.

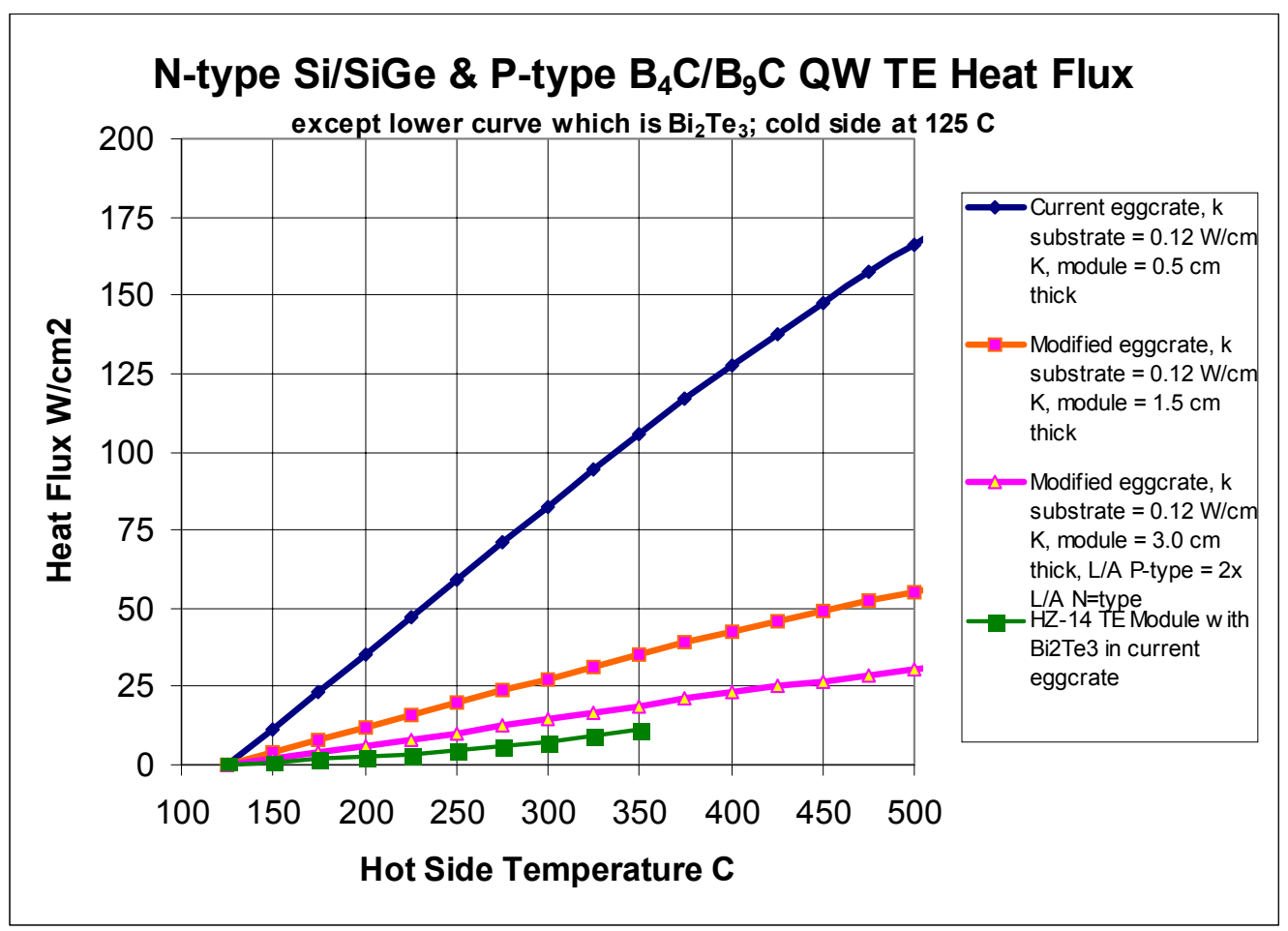

Figure 48. N-Type Si/SiGe P-type $\mathrm{B}_{4} \mathrm{C} / \mathrm{B}_{9} \mathrm{C}$ QW TE Heat Flux 
Extremely high powers are possible with the current eggcrate design. However, the heat flux cannot be sustained at these conditions for most applications. The following chart (Figure 49) shows the trade-off between heat transfer and QW TE module performance.

Hot and cold side thermal conductances as well as QW module thermal conductances can be optimized to realize the benefits of QW materials. By improving the hot and cold heat transfer coefficients; this results in higher hot side and cooler cold side temperatures. The net effect will be an increase in temperature difference across the TE generator, and more efficient power output.

Figures 50,51 and 52 show conceptual designs for the $5 \mathrm{~kW} \mathrm{QW} \mathrm{Thermoelectric} \mathrm{Generator} \mathrm{as} \mathrm{it} \mathrm{is}$ now envisioned. This is one of two QWTE generators for the $10 \mathrm{~kW}$ underarmor configuration for the Stryker vehicle. Future phases will prepare a detailed design and prepare this concept for commercialization.

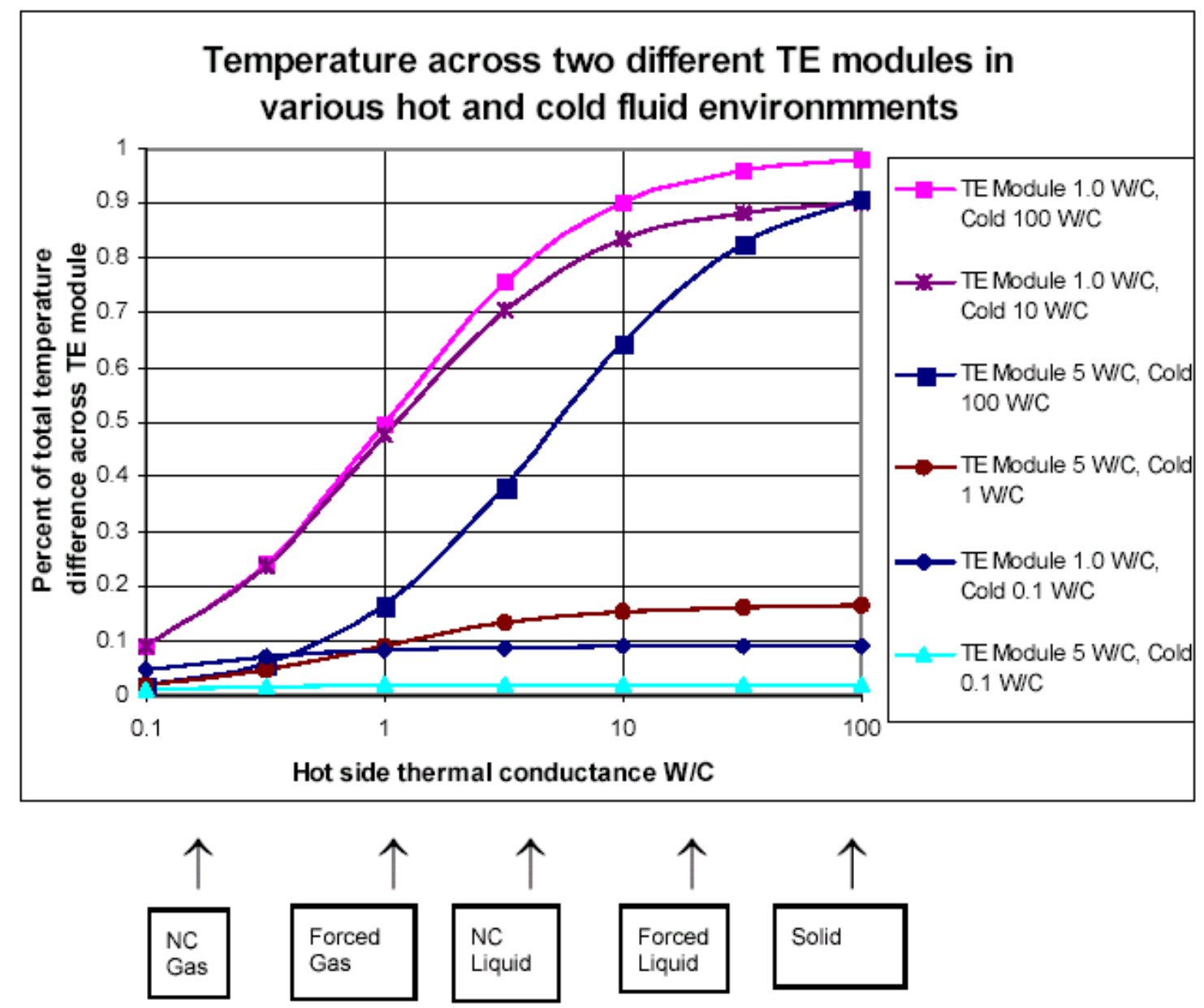

Figure 49. Temperature Across Two Different TE Modules in Various Hot and Cold Fluid Environments 


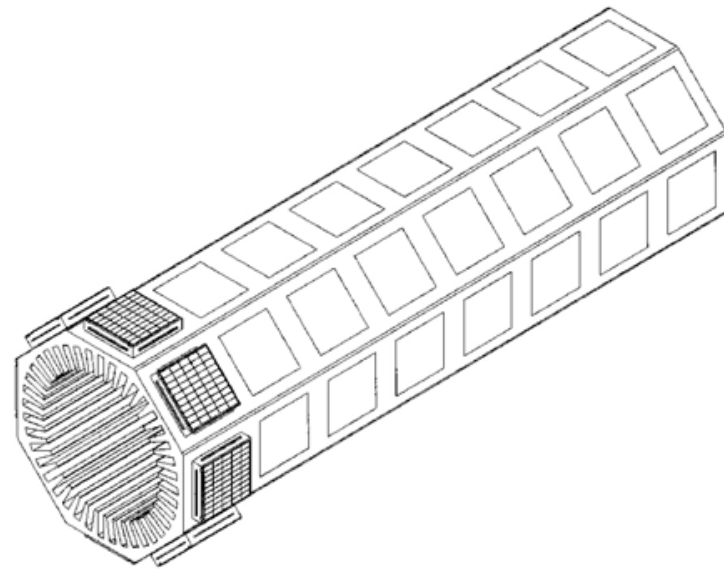

Figure 50. Portion of $5 \mathrm{kWe}$ QW Thermoelectric Generator Showing One Row of Quantum Well Thermoelectric Modules Surrounding Waste Heat Stream

\section{P-type $\mathrm{B}_{4} \mathrm{C} / \mathrm{B}_{9} \mathrm{C}$ with films} grown on substrate

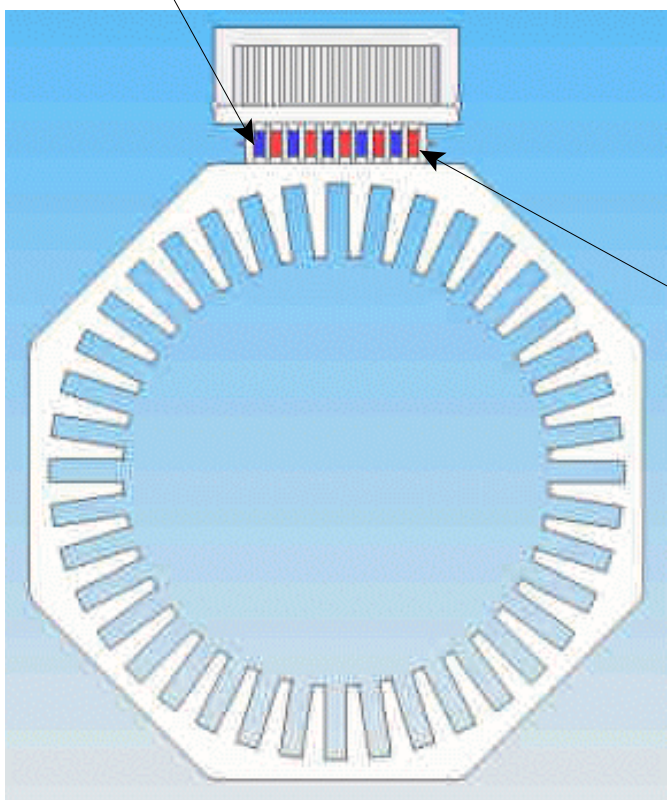

Figure 52. Section Through One Quantum Well Module Showing N and P Legs, Coolant Heat Exchanger and Central Gas Exhaust. Parasitic heat losses are reduced with proposed improvements in substrate.

\section{Quantum Well}

Coolant Heat Exchanger

Thermoelectric Module (2.35 x 2.35 in. $\times 0.5 i n$.

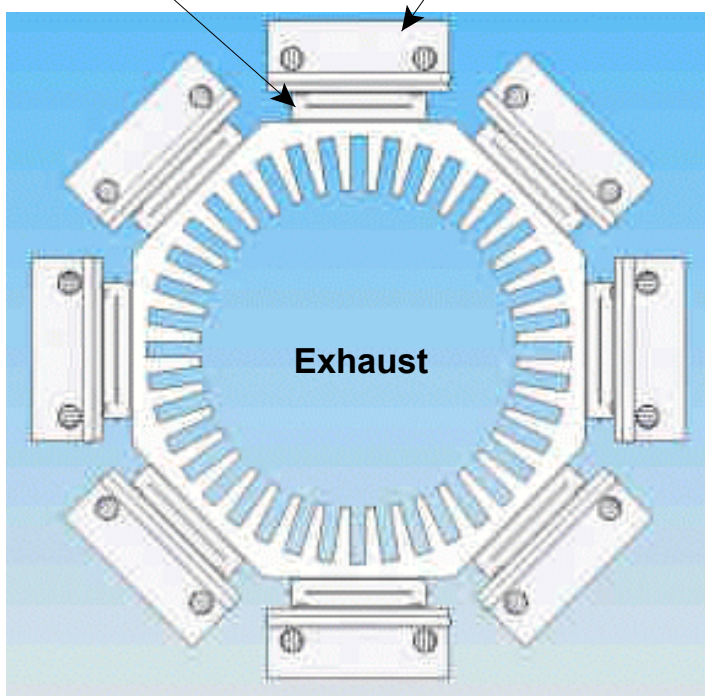

Figure 51. Waste Heat Recovery Thermoelectric Generator With Quantum Well Thermoelectric Modules
N-type Si/SiGe with films grown on substrate 


\section{PRODUCTS DEVELOPED}

\section{4-A. PUBLICATIONS AND PAPERS}

1. John C. Bass, Daniel T. Allen, Saeid Ghamaty, and Norbert B. Elsner, "New Technology for Thermoelectric Cooling", 20 $0^{\text {th }}$ IEEE Semi-Therm Symposium, 2004.

2. J. C. Bass, "Thermoelectric Generators for Diesel Truck", Chapter in The New Edition of Thermoelectric Energy Conversion Systems, published July 31, 2004 (in Japanese).

3. N. B. Elsner, "Fabrication of MilliWatt Modules", Chapter in The New Edition of Thermoelectric Energy Conversion Systems, published July 31, 2004 (in Japanese).

4. A. S. Kushch, J. C. Bass, S. Ghamaty, N. B. Elsner, R. A. Berstrand, D. Furrow and M. Melvin, "Thermoelectric Development of Hi-Z Technology", Proceedings, $7^{\text {th }}$ DEER Conference, Office of Scientific and Technical Information, Portsmouth, VA, 2001.

5. "Proof-of-Principle Test for the Thermoelectric Generator for Diesel Engines", Final Report, Hi-Z Technology, Inc., HZ 72691-1, 1991.

6. N. B. Elsner, S. Ghamaty, J. H. Norman, J. C. Farmer, R. J. Foreman, L. J. Summers, M. L. Olsen, P. E. Thompson, and K. Wang, "Thermoelectric Performance of Si0.8Ge0.2/Si Hetrostructures by MBE and Sputtering", Proceedings, $13^{\text {th }}$ International Conference on thermoelectrics, AIP Press, Kansas, City, MO, 1994.

7. A. S. Kushch, B. Helenbrook and C. J. Richter, "The Effect of an Exhaust Thermoelectric Generator on a GM Sierra Pick-Up Truck", 2004 Diesel Engine Emission Reduction Conference, San Diego, CA, August 29-September 2, 2004.

8. John C. Bass, Daniel J. Krommenhoek, Aleksandr S. Kushch, and Saeid Ghamaty. "Development of an Underarmor 10 Kilowatt Thermoelectric Generator Waste Heat Recovery System for Military Vehicles," 2004 Diesel Engine Emissions Reduction Conference, San Diego, CA, August 29-September 2, 2004.

9. Eric F. Thacher, Brian T. Helenbrook, Madhal A. Karri, Marc S. Compeau, Aleks S. Kushch, Norbert B. Elsner, Mohinder S. Bhatti, and John O'Brien, "Electric Energy Generation From the Exhaust of a Light Truck", 2004 DOE/EPRI High Efficiency Thermoelectrics Workshop, San Diego, CA, February 17-20, 2004.

10. Eric F. Thacher, Brian T. Helenbrook, Madhal A. Karri, Marc S. Compeau, Aleks S. Kushch, Norbert5 B. Elsner, Mohinder, S. Bhatti, John O'Brien and Francis Stabler, "Thermoelectric Energy Recovery from the Exhaust of a Light Truck", 2003 Diesel Engine Emission Reduction Conference, Newport, Rhode Island, August 24-28, 2003.

11. Richard A. Bergstrand and Aleksandr S. Kushch, "Thermoelectric Technology for Automotive Applications", 2004 Diesel Engine Emission Reduction Conference, San Diego, CA, August 25-29, 2002.

12. A. S. Kushch, J.C. Bass, N.B. Elsner, R. Bergstrand, D. Furrow and M. Melvin, "Thermoelectric Development at Hi-Z Technology", Diesel Engine Emissions Reduction Workshop, Portsmouth, VA, August 6-10, 2001.

13. John C. Bass, Aleksandr S. Kushch, and Norbert B. Elsner, "Thermoelectric Generator (TEG) for Heavy Diesel Trucks", $20^{\text {th }}$ International Conference on Thermoelectrics, June 8-11, 2001, Beijing, P.R. China. 


\section{4-B. HARDWARE}

\section{DTTEG}

$1 \mathrm{~kW}$ Thermoelectric Generator for Diesel Trucks (TEG MOD 2)

Patents Developed

Patent 5,625,245 - Thermoelectric Generator, Filed 10/19/93

Patent 5,892,656 - Thermoelectric Generator, Filed 05/20/96

\section{AETEG}

200 Watt Thermoelectric Generator for Automobiles/Trucks

\section{LTETG}

300 Watt Thermoelectric Generator for Light Trucks

\section{SUMMARY OF ACCOMPLISHMENTS}

\section{DTTEG, AETEG and LTETG}

- Achieved 543,000 equivalent mils on TEG Mod 1

- Achieved $1 \mathrm{~kW}$ output in test cell with $22^{\circ} \mathrm{C}$ cooling water

- Achieved $528 \mathrm{~W}$ output on road tests with $90^{\circ} \mathrm{C}$ cooling water

- PACCAR advanced vibration isolators were successful

- Data generated for conceptual design of $10 \mathrm{~kW}$ TEG (two $5 \mathrm{~kW}$ TEG's thermally in Series)

- Bulk modules of improved design were developed

- Clarkson AETEG and Ohio State LTETG were designed and tested

- Ruggedness of DTTEG was improved

\section{QUANTUM WELL FILM AND MODULE DEVELOPMENT}

- New 34 inch diameter sputtering machine was purchased and installed (shared among four contracts)

- Four QW couples fabricated and tested

- A mockup of a $2 \frac{1}{2}$ Watt QW module has been prepared

- Conceptual design of 80 Watt QW modules prepared for $10 \mathrm{~kW} \mathrm{TEG}$

- Electron beam hot wall apparatus developed and tested 


\section{CALCULATED OVERALL ECONOMICS FOR COMMERCIALIZATION}

- $\quad 1 \mathrm{~kW}$ TEG potential fuel savings of \$750/year with \$2/gallon diesel fuel $5 \mathrm{~kW}$ TEG potential fuel savings of $\$ 3000 /$ year with $\$ 2 /$ gallon fuel

- Estimated payback of 5 years, 1 kW, 14 Watt bulk modules @ \$2/Watt

- Estimated payback of 2 years, 5 kW, 80 Watt QW modules@ @ \$0.84/Watt

- Estimated payback of 1 year, 5 kW, 80 Watt QW modules @ \$0.23/Watt

\section{RECOMMENDATIONS}

- Continue development of DTTEG through the $10 \mathrm{~kW}$ Stryker program and various other TEG programs

- Seek additional funding and partners to carry the TEG through value engineering and commercialization

- Accelerate the QW film production and module assembly through advanced automation to reach $\$ 0.21$ per Watt QW module SP 